Volume (5) No. (1) 2022

تصميم فيديو رقمي قائم على السرد القصصي في بيئة تعلم إلكترونية وأثره في تنمية الدافعية العقلية والتحصيل الأكاديمسي لدى طلاب كلية التربية بجامعة الملك سعود

د. دل ملطان بن هويدي المطيري 
تصميم فيديو رقمي قائم على السرد القصصي في بيئة تعلم إلكترونية وأثره في تنمية الدافعية العقلية والتحصيل الأكاديمي لدى طلاب كلية التربية بجامعة الملك سعود د. سلطان بن هويدي المطيري أستاذ تقنيات التعليم المشارك، كلية التربية - جامعة الملك سعود، السعودية sabokhaled@ksu.edu.sa

$$
\begin{aligned}
& \text { قبلت للنشر في r/ / / / I / }
\end{aligned}
$$

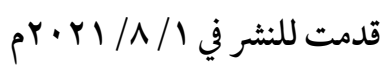

الملخص: هدف البحث إلى تصميم فيديو رقمي قائم علن السرد القصصي في بيئة تعلم إلكترونية، ومن ثم استخدامه لمعرفة أثره في تنمية الدافعية العقلية والتحصيل الأكاديمي لدني طلاب كلية التربية بجامعة الملك سعود. ولتحقيق هذا الهدف تم اختيار عينة عشو ائية تكونت من (r (7) طالبًا من طلاب البكالوريوس في كلية التربية، تم توزيعهم عشو ائيًا إلن مجموعتين: المجموعة التجريبية تكونت من (· (r) طالبًا تعلموا باستخدام الفيديوهات الرقمية القائمة علن السرد القصصي في بيئة التعلم الإلكترونية، والمجموعة الضابطة تكونت من (YY) طالبًا تعلموا باستخدام الطريقة المعتادة، وذلك في مقرر "دمج التقنية في بيئة التعلم"، وقد تم استخدام مقياس الدافعية العقلية، واختبار تحصيلي. كما تم استخدام اختبار (ت) لتحليل نتائج البحث، وقد توصلت الدراسة إلى فاعلية استخدام الفيديو الرقمي في بيئة

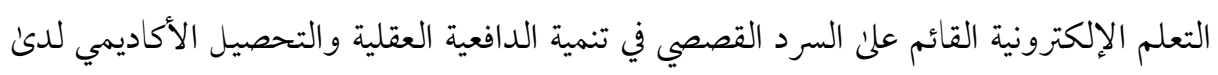
طلاب كلية التربية بجامعة الملك سعود. الكلمات المفتاحية: الفيديو الرقمي، السرد القصصي، الدافعية العقلية، التحصيل الأكاديمي. 


\title{
Designing a digital video based on storytelling in an e-learning environment and its effect on developing mental motivation and academic achievement among students at College of Education, King Saud University
}

\author{
Dr. sultan Howedey Almutairy
}

Associate Professor of Educational Technology, College of Education, King Saud University, Saudi Arabia, sabokhaled@ksu.edu.sa

Received August 1st, 2021

Accepted November 2, 2021

\begin{abstract}
This research aimed to design a digital video based on storytelling in an elearning environment, and then using it to find out its effect on developing mental motivation and academic achievement among students at College of Education, King Saud University. To achieve this goal, a sample of (62) students from College of Education at King Saud University was selected. The researcher divided them into experimental group of (30) students, who studied by using digital videos which designed based on storytelling in an e-learning environment, and control group of (32) students, who studied by traditional method, both groups were enrolling in the course of "Integrating Technology in Education". The mental motivation measurement and academic achievement test were used as well as T-test for analyzing the research data. This research found the effectiveness of using digital video in an e-learning environment based on storytelling in developing mental motivation and academic achievement among students at College of Education, King Saud University.
\end{abstract}

Keywords: digital video, storytelling, mental motivation, academic achievement. 
يعد الفيديو أحد كائنات التعلم الرقمية التي تستخدم بكثرة في العملية التعليمية وذلك لاحتوائه علن العديد من المزايا، فهو من أكثر كائنات التعلم التي تجذب وتساعد الطلاب علئ التفاعل البناء، لأنه يجمع بين عدة كائنات مثل: الصور و الرسومات الثابتة والمتحركة، والأصو ات والمؤثرات الصوتية. كذلك يستخدم في شرح الموضوعات المجردة والتي يصعب شرحها بالنصوص أو الصور الثابتة، لأنه يمكن أن يعرض أحداثًا واقعية، كما يستطيع الطلاب تكرار مشاهدة الفيديو أكثر من مرة، ويستخدم في العديد من المو اقف التعليمية لتسهيل عمليتي التعليم والتعلم.

وللفيديو أهمية كبيرة في التعليم، وذلك لإيصال أكبر قدر من المعلومات إلى المتعلمين، وجذب انتباهـم طو ال الوقت، وتحفيزهم بشكل جيد لمشاهدة ومعرفة معلومات جديدة، وقد أثبتت الدراسات والبحوث العلمية فاعليته في العملية التعليمية مثل دراسات كل من Hwang, Chang, \& Hsu, .(Rahimi \& Yadollahi, 2017 ؛Balaman, 2017 ؛Chang, 2013

يعرف الفيديو التعليمي الرقمي بأنه بيانات رقمية يتم تسجيلها وتحريرها ومعالجتها وتخزينها

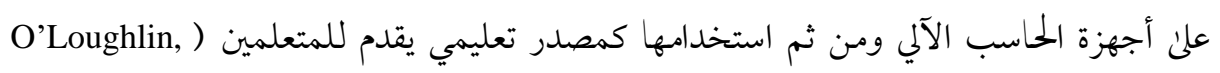
Nichroinın, \& O’Grady, 2013 رقمية مسجلة ومحفوظة علن وسائط رقمية أو مواقع ويب تحت الطلب". يتميز الفيديو التعليمي الرقمي بالعديد من المميزات والإمكانيات من حيث سعته وقدرته علن عرض كل أنواع الوسائط التعليمية، وكذلك قدرته علن مساعدة الطلاب علن فهم الحقائق، والمفاهيم والتعميات والعمليات والإجراءات، التي يصعب فهمها من خلال أي وسيط تعليمي آخر (خميس،

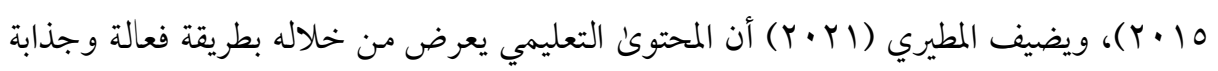
ومؤثرة في المتعلم لاحتو ائه علن عدة وسائط تخاطب عدة حواس، لذلك فهو يعد مصدر ا تعليميا شاملا يجمع بين الصوت و الصورة والحركة، ويتميز بسهولة تسجيل لقطاته من قبل المعلمين، ويحدد بيهيشتي و تاسبولات، كايا، سابانكا (Beheshti, Taspolat, Kaya, \& Sapanca, 2018) بعض المميزات 
للفيديو التعليمي بأنه يزيد من التفاعل الاجتماعي بين المتعلمين، و إمكانية عرضه مرات عديدة، ويوفر لهم بيئة تعليمية فردية، كما أنه يوفر لهم فرصا للتعلم الذاتي، وقابلية تداول الفيديو التعليمي بينهم مباشرة عن طريق الإنترنت، أو تسجيله ليتم الرجوع إليه في أي وقت.

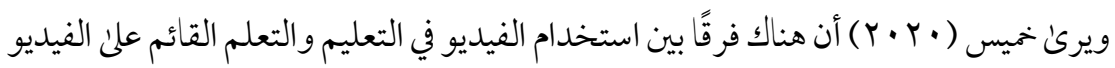
Video-Based Learning حيث يستخدم الفيديو في التعليم كوسيط مكمل أو إثرائي ضمن المواد التعليمية الأخرىن، بينما التعلم القائم على الفيديو فهو يعد بيئة تعليمية كاملة تعتمد علن الفيديو باعتباره المصدر الأساسي في عملية التعلم كما هو الحال في بيئة Massive Open Online Courses، وبيئة التعلم الخاصة بأكاديمية خان، حيث تعتمد العملية التعليمية في تلك البيئات بشكل كامل على الفيديو، الذي يعد نقطة الانطلاق إلى مصادر التعلم الأخرىن، عكس استخدام الفيديو في التعليم الذي تكون فيه المصادر الأخرى هي نقطة الانطلاق إلى الفيديو.

يستخدم الفيديو التعليمي الرقمي بعدة أنواع (Vieira, Lopes, \& Soares, 2014): منها المحاضرات المسجلة، المحاضرات المباشرة، والعروض التقديمية الصوتية، ومحاضرات الفيديو التفاعلية. وقد زاد استخدام الفيديو في عملية التعلم بعد ظهور مواقع التشارك في الفيديو وخاصة موقع اليوتيوب، والذي تأسس عام ه •.r، وبعدها تطور إلى اليوتيوب التربوي علن الموقع (r). http://www.youtube.com/edu وبالرغم من التأكيد على فاعلية تلك البيئات في نواتج التعلم، فقد وجد بعض الباحثين فيها نواحي قصور، فقد قام يوسف، تشاتي، وستشرودر (Yousef, Chatti, \& Schroeder, 2014) بمراجعة وتحليل البحوث التي أجريت علن بيئات التعلم الإلكتروني القائمة علن الفيديو بين عامي

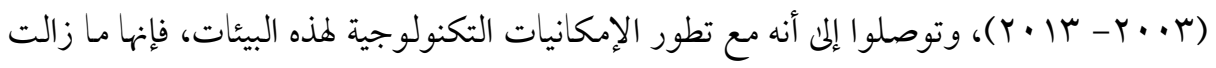
تعاني من نواحي قصور عديدة، ولم يتحقق الهدف المرجو منها، الأمر الذي أدى إلى وجود صعوبات عند بعض المتعلمين الملتحقين بهذه البيئات وتسربهم منها، وتوصلت تلك البحوث أيضًا إلى وجود نتائج متناقضة لفاعلية استخدام الفيديو الرقمي في التعليم، كما أن استخدام العديد منها كان بدون 
استراتيجيات تعليم واضحة ومناسبة للمتعلمين، وأيضًا لم يكن تصميمها بالشكل الذي يثير دافعيتهم

$$
\text { ويجذب انتباههم. }
$$

وبمر اجعة البحوث والدراسات التي قارنت بين التعلم القائم علن الفيديو والتعليم التقليدي، فإن بعض البحوث أثبتت فاعلية التعلم القائم علن الفيديو بالمقارنة بالتعليم التقليدي، حيث أظهرت نتائج دراسة تشاتوكي، حرود، خالدي، وبيناني (Chtouki, Harroud, Khalidi, \& Bennani, 2012) تفوق بلتئي الطلاب الذين استخدمو افيديوهات اليوتيوب في الاختبار المعرفي علن الطلاب الذين استخدمو الطريقة الاعتيادية، وأظهرت نتائج دراسة هسو وآخرون (Hsu, et al., 2013) بأن الطلاب الذين استخدمو الطين الفيديو التعليمي كانت مهارة الاستماع وحفظ المفردات لديهم في مادة اللغة الإنجليزية أفضل من الطلاب الذين تعلموا بالطريقة التقليدية، وأظهرت نتائج دراسة العجرمي (19 • Y) تفوق الطالبات التي درسن باستخدام مقاطع الفيديو التعليمية عبر اليوتيوب في تنمية إنتاج القصص الرقمية علن الطالبات التي

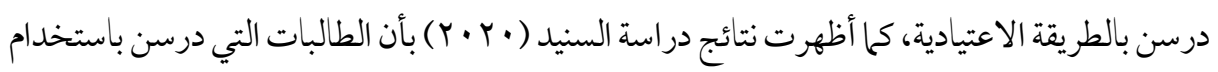
الفيديو التعليمي في مادة الجغرافيا كان مستوئ التحصيل الدراسي لديهن أفضل من مستوئ الطالبات

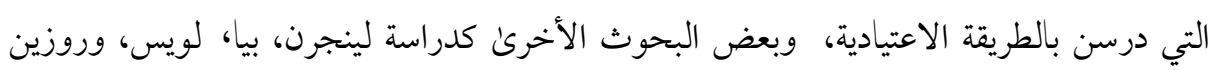
(Lindgren, Pea, Lewis, \& Rosen, 2007)

$$
\text { وبين التعليم التقليدي. }
$$

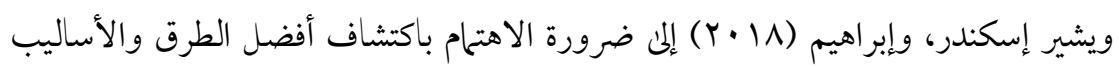
والاستراتيجيات التي تساهم في زيادة فاعلية الفيديو التعليمي؛ لذا فإنه توجد حاجة إلى تحسين التعلم القائم علن الفيديو، و التغلب على نواحي القصور فيه، باستخدام مداخل واستراتيجيات تعليم مناسبة، تجذب انتباه المتعلمين، ومن أهم هذه المداخل السرد القصصي. يعرف رحيمي، ويدو لاهي (Rahimi \& Yadollahi, 2017) السرد القصصي بأنه "مزيج من الوسائط المتعددة لإثراء المحتون التعليمي المنطوق والمكتوب وتقديمه للمتعلمين على شكل قصه رقميه" (ص. r) (Balaman, 2017) "أداة تعليمية شيقة وفعاله تستخدم في كل مجالات

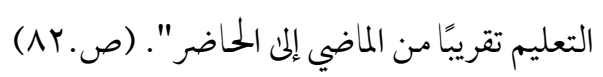


وللسرد القصصي فو ائد عديدة في الميدان التعليمي كما أوردها دهايمش (Dehaimesh, 2016) فمنها أنه يساعد المتعلمين ليكونوا أكثر ثقة في التعليم، ويحسن شعورهم ويساعدهم علئ التواصل من خلال مشاعرهم، ويزيد من انخراطهم في أنشطة التعلم، وهذا يؤدي إلى زيادة تحصيلهم العلمي، وزيادة دافعيتهم نحو التعلم.

وقد أثبتت البحوث والدراسات فاعلية استخدام السرد القصصي الرقمي في العملية التعليمية،

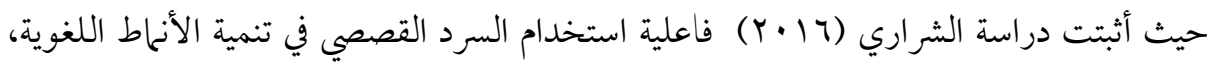
والتفكير، وعادات العقل لدئ طلاب المرحلة الابتدائية، وأثبتت دراسة بالمان (Balaman, 2017) فاعلية استخدام السرد القصصي الرقمي في تحسين كفاءة وأداء طلاب المدارس المهنية في الفصول الافتراضية، وأثبتت دراسة رحيمي، ويدولاهي (Rahimi \& Yadollahi, 2017) فاعلية استخدام السرد القصصي الرقمي في تنمية مهارات الكتابة والقراءة لدىن متعلمي اللغة الإنجليزية كلغة أجنبية، و أثبتت دراسة الزهد (1) · ب بأن استخدام السرد القصصي الرقمي في تعليم اللغة الإنجليزية له آثار إيجابية على مهارات الطلاب ودافعيتهم نحو التعلم، كما أثبتت دراسة سوالمه (Y.Y.Y) فاعلية استراتيجية السرد القصصي في تحسين التحصيل الأكاديمي لدى المتعلمين في مادة الرياضيات،

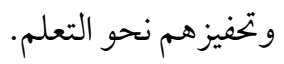

من جهة أخرىن تعد الدافعية العقلية لدىن المتعلم من أهم الشروط الأساسية التي يتوقف عليها تعلمه في العديد من المجالات مثل أساليب التفكير وتكوين الاتجاهات والتحصيل الأكاديمي لديه، فالمتعلم يتميز بالنشاط والرغبة في بعض المو اقف أكثر من مو اقف أخرىن، وهذا يرجع المى مستوى دافعيته العقلية (الشريم، 7 • • ). وقد حدد جيانكارلو وفاشيون Giancarlo, \& Facione أن الدافعية العقلية

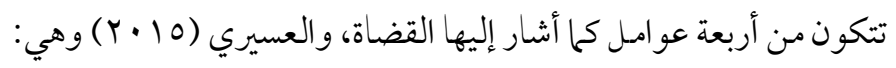

ا. التركيز العقلي Mental focus: تميز المتعلم الذي لدية القدرة علن التركيز العقلي بالمثابرة و التركيز و التنظيم، و التي تنعكس علن إنجازه في كل ما يقدم له من مهام و أعمال و أنشطة بدون تأجيل أو تسويف، ويتميز باندماجه في الأنشطة التي يقوم بها بكل متعة وراحة. 
r. Learning Orientation يتميز المتعلم الذي لديه توجه نحو التعلم

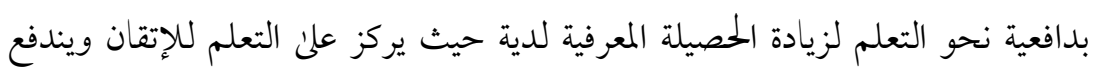
للبحث والاستكشاف بشكل فعال، ويكون أكثر اندماجًا في التعلم.

r. الحل الإبداعي لحل المشكلات Creative Problems Solving: يتميز المتعلم الذي يمتلك قدرًا من الإبداع في حل المشكلات أن لديه أفكار وحلول غير تقليدية تتسم بالأصالة، وهذا

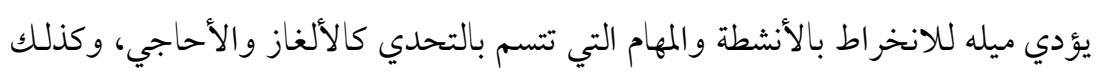
يتميز بالرضى عن ذاته عند أدائه لتلك الأنشطة والمهام. ع. التكامل المعرفي Cognitive Integrity: يظهر هذا العامـل قدرة المتعلم على الاستخدام الجيد

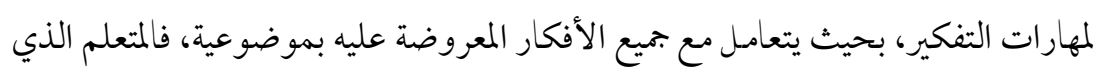
يتصف بالتكامل المعرفية يكون باحثًا عن الحقيقة ومتفتح الذهن، ولديه خبرات بديلة في بلدي

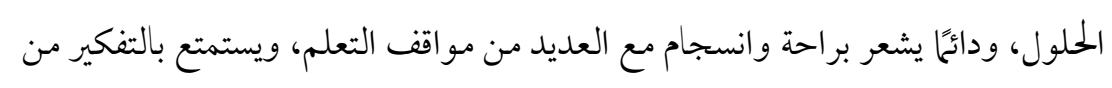

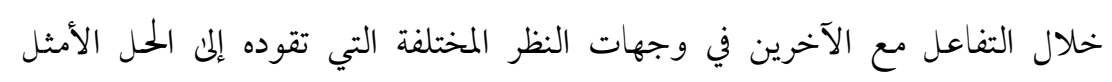
لل لمشكلات.

إن للدافعية العقلية دورًا مهكًا في عملية التعليم، حيث تعد من الأهداف المنشودة لأي نظام تعليمي؛ كونها تمثل الأسس العامة لعملية التعلم، وطرق التكيف مع العالم الخارجي و اكتساب الخبرات المختلفة وتحقيق الأهداف، والصحة النفسية للمتعلمين، كما أنه لا يحدث تعلم بدون دوافع أو رغبة في

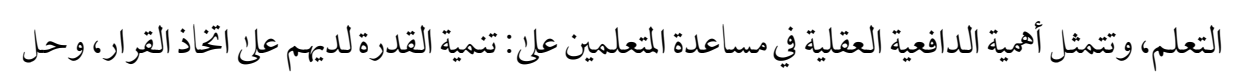
المشكلات بطرق إبداعية، ولفت انتباههم وتركيزهم عند حل المشكلات المطروحة وأداء المهام الموكلة

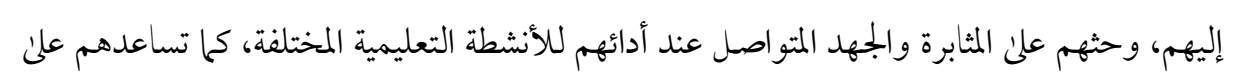
القيام بالعمليات العقلية العليا، وذلك لتوليد حلول مبتكرة غير مألوفة لديهم، والاعتهاد على الذات

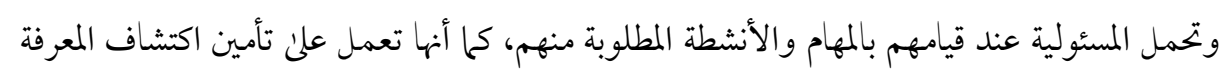

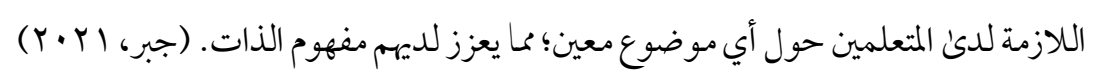


وقد أجريت العديد من البحوث والدراسات حول الدافعية العقلية وأهميتها في عملية التعلم، حيث أظهرت نتائج دراسة القضاة، والعسيري (10 · ب ) أن طلاب كلية التربية بجامعة الملك سعود يمتلكون الدافعية العقلية بدرجة متوسطة، الأمر الذي يقتضي التركيز على تنمية هذا المتغير المهم، حيث

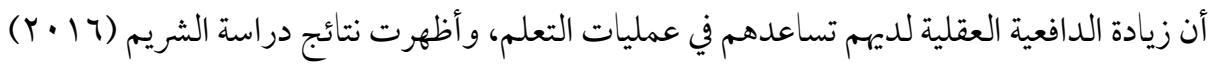
بأن الدافعية العقلية لها قدرة على التنبؤ بالمعدل والتحصيل الأكاديمي للطلبة، وأيضًا أظهرت نتائج دراسة عبد الرحيم (1) • (Y) وجود علاقة ارتباطية مختلفة الدلالة بين الدافعية العقلية بأبعادها وكفاءة التعلم الإيجابية، وأظهرت نتائج دراسة رشيد (19 (Y) وجود علاقة ارتباطية إيجابية بين الدافعية العقلية لطلاب الدراسات العليا والتوافق الأكاديمي لديهم، حيث أنه كلما كانت البيئة التعليمية شيقة وممتعة فإن ذلك يؤدي إلى ارتفاع مستوى دافعيتهم العقلية ورغبتهم في التعلم، وأظهرت نتائج دراسة العبيدي، والعزاوي (• • • (Y) وجود علاقة ارتباطية مو جبة بدرجة جيدة بين الدافعية العقلية وأساليب التعلم حيث أنه كلما زادت الدافعية العقلية لدئ الطلاب فإن مستوى تعلمهم يرتفع بدرجة أكبر. ومن ناحية اخرىن، فإن عملية الإبداع لدئ المتعلم يعتبر نتيجة للدافعية العقلية، حيث أنه

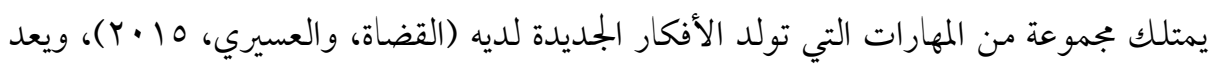
السرد القصصي من الطرائق التي تنمي التفكير الإبداعي للمتعلمين، وذلك لما تتضمنه من عناصر مختلفة، وعلاقات تنظم في تتابع معين للأحداث، وما تتطلبه من عمليات الفهم، والتطبيق، و التحليل، لذا فإن السرد القصصي في بيئات التعلم الإلكتروني يزيد من الدافعية العقلية لدى المتعلم، حيث أن الدافعية العقلية يتم تحفيزها في حال تهيئة بيئات دراسية إيجابية ومشجعة على التعليم، فإن بيئات التعليم الإلكترونية تعد من أفضل ما يقدم للطالب لتحفيز الدافعية العقلية لديه. لذلك يرتبط استخدام بيئات التعلم الإلكترونية بالدافعية العقلية للمتعلم، حيث يتطلب ذلك مشاركة المتعلم عقليًا في التعلم وتهيئته للقيام بالأنشطة المختلفة في العملية التعليمية. وهذا يتفق مع ما توصلت إلية نتائج دراسة لين، تشن، ونين (Lin, Chen, \& Nien, 2014) التي أظهرت نتائجها وجود فروق دالة إحصائية بين استخدام استراتيجيات التعلم الإلكتروني والطرائق التقليدية، وأثرهما على 
التحصيل والدافعية لدى الطلاب لصالح المجموعة التي درست باستخدام استراتيجيات التعلم

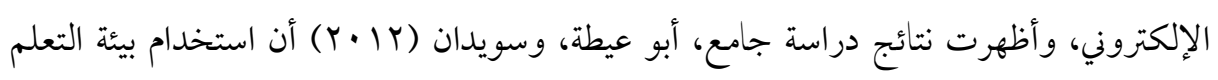
المدمج وتنوع أساليبه ينمي الدافعية نحو التعلم لدئ الطالبات، كما أن ترتيب وتنظيم المادة التعليمية في أجزاء مترابطة ومتكاملة في بيئة التعلم المدمج يؤدي إلى تحقيق مبادئ التعلم، وهي الارتياح والتحدي والعمق وزيادة الدافعية لديهن.

ويهدف البحث الحالي إلى تصميم فيديو رقمي قائم علن السرد القصصي في بيئة تعلم إلكترونية، ومن ثم استخدامه لمعرفة أثره في تنمية الدافعية العقلية والتحصيل الأكاديمي لدى طلاب كلية التربية بجامعة الملك سعود مشكلة البحث

تمكن الباحث من بلورة مشكلة البحث، وتحديدها، وصياغتها، من خلال المحاور الآتية: أولاً: الحاجة إلى تنمية الدافعية العقلية والتحصيل الأكاديمي لدى طلاب كلية التربية بجامعة الملك سعود. لاحظ الباحث من خلال تدريسه لطلاب كلية التربية وجودصعوبة في الجانب التطبيقي لمقرر "دمج التقنية في بيئة التعلم"، وعدم قبولهم لما يقدم لهم، وتأخرهم في تسليم ما يطلب منهم من أنشطة

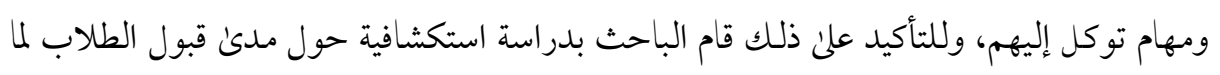
يقدم لفم من أنشطة ومهام في هذا المقرر، وجاءت النتائج أن · V٪ يعانون من بعض المشكلات في هذا المقرر، ولا يوجد لديهم قبول فيما يقدم لهم من أنشطة ومهام، ونظر الوجود عدد من الدراسات كدراسة

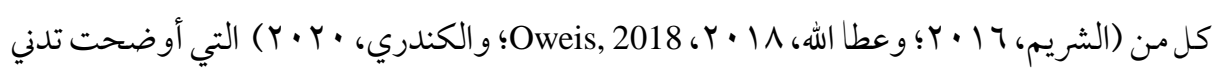
مستوئ الدافعية للتعلم والتحصيل الأكاديمي، وكذلك وجود عدد من الدراسات كدراسة كل من

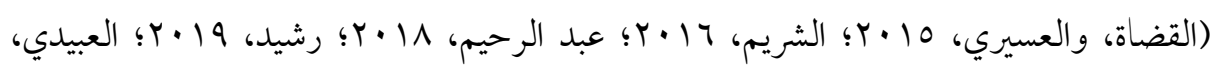
والعزاوي، ·r ·r) التي تؤكد علن أهمية تنمية الدافعية العقلية ودورها في حصول التعلم وزيادة 
التحصيل الأكاديمي، وتأتي هذه الدراسة في محاولة لتنمية الدافعية العقلية والتحصيل الأكاديمي لدنا طلاب كلية التربية بجامعة الملك سعود من خلال مقرر "دمج التقنية في بيئة التعلم"، وهو ما يهدف إليه البحث الحلالي.

ثانيًا: الحاجة إلى تطوير فيديو رقمي قائم على السرد القصصي في بيئة تعلم إلكترونية لتنمية الدافعية العقلية والتحصيل الأكاديمي لدى طلاب كلية التربية بجامعة الملك سعود من خلال مقرر "دمج

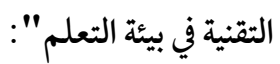

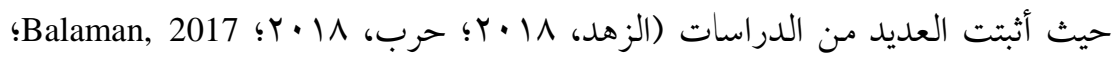

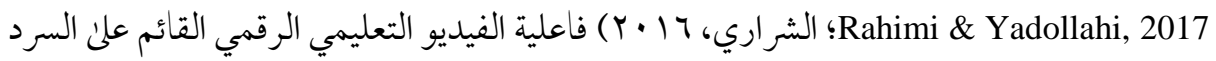
القصصي، تأتي هذه الدراسة في محاولة لتنمية الدافعية العقلية والتحصيل الأكاديمي لدئ طلاب كلية التربية بجامعة الملك سعود، من خلال تصميم فيديو رقمي قائم على السرد القصصي في بيئة تعلم إلكترونية لتنمية الدافعية العقلية والتحصيل الأكاديمي لدى طلاب كلية التربية بجامعة الملك سعود فإنه توجد حاجة إلى تطوير فيديو رقمي قائم علن السرد القصصي في بيئة تعلم إلكترونية. وعلن ذلك، يمكن تحديد مشكلة البحث الحالي، وصياغتها في العبارة التقريرية الآتية: "يو جد ضعف في الدافعية العقلية والتحصيل الأكاديمي في مقرر "دمج التقنية في بيئة التعلم" لدى طلاب كلية التربية بجامعة الملك سعود ولعلاج هذا الضعف سوف يتم تصميم فيديوهات رقمية قائمة على السرد القصصي في بيئة تعلم إلكترونية". أسئلة البحث

$$
\text { في ضوء ما سبق تم صياغة السؤال الرئيس للبحث في الآتي: }
$$

كيف يمكن تصميم الفيديو الرقمي القائم علن السرد القصصي في بيئة تعلم إلكترونية لتنمية الدافعية العقلية والتحصيل الأكاديمي لدئ طلاب كلية التربية بجامعة الملك سعود؟ ويتفرع من هذا السؤال الرئيس الأسئلة الأتية: 
ا. ما معايير تصميم الفيديو الرقمي القائم علن السرد القصصي في بيئة تعلم إلكترونية لتنمية

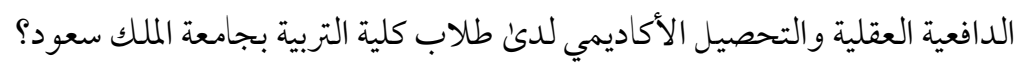
r. ما التصميم التعليمي للفيديو الرقمي القائم على السرد القصصي في بيئة تعلم إلكترونية لتنمية الدافعية العقلية والتحصيل الأكاديمي لدني طلاب كلية التربية بجامعة الملك سعود؟ r. مـا أثر الفيديو الرقمي القائم علن السرد القصصي في بيئة تعلم إلكترونية في تنمية الدافعية

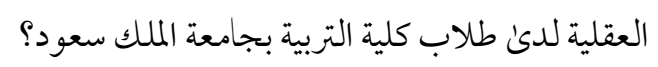

ع. ما أثث الفيديو الرقمي القائم علن السرد القصصي في بيئة تعلم إلكترونية في التحصيل

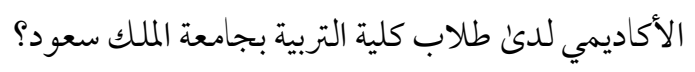

$$
\text { أهداف البحث }
$$

يسعى البحث الحلاي إلى تصميم فيديو رقمي قائم علن السرد القصصي في بيئة تعلم إلكترونية، ومن ثم استخدامه لمعرفة أثره في تنمية الدافعية العقلية والتحصيل الأكاديمي لدىن طلاب كلية التربية بجامعة الملك سعود.

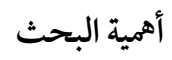
يمكن إيجاز أهمية البحث بالآتي:

ا . توجيه نظر مطوري المناهج ومصممي التعليم نحو تصميم الفيديو الرقمي القائم علن السرد القصصي في بيئات التعلم الإلكترونية.

r. . توجيه نظر أعضاء هيئة التدريس نحو استخدام الفيديو الرقمي القائم علن السرد القصصي في بيئة تعلم إلكترونية. 
ا . الحدود الموضوعية: تمثلت في مقرر (Y Y Y) وسل "دمج التقنية في بيئة التعلم". r. الحدود البشرية: تتمثل في طلاب كلية التربية بجامعة الملك سعود. r. الحمدود الزمنية: تتمثل في الفصل الثاني للعام الدراسي ه ؟ع اهـ. ع. الحدود المكانية: تتمثل في كلية التربية بجامعة الملك سعود.

\section{بجتمع وعينة البحث}

تكون بجتمع البحث من جميع الطلاب المسجلين في مقرر (Y Y Y) وسل "دمـج التقنية في بيئة

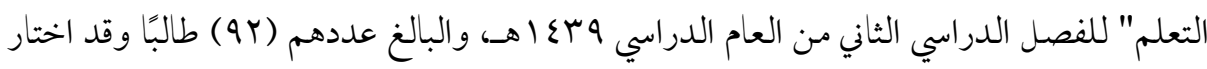
الباحث بجمع البحث ليكون هو عينة البحث، وقام الباحث بتقسيم العينة عشوائيا إلى مجموعتين متساويتين بكل مجموعة عدد (7) ) طالبًا الأولى كمجموعة ضابطة والأخرى كمجموعة تجريبية، وقد

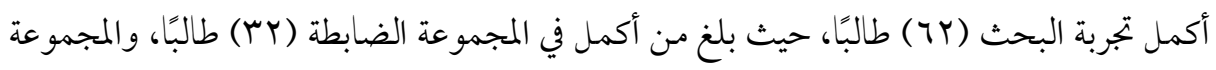
التجريبية (··) مالبًا.

\section{منهج البحث}

نظرًا لأن هذا البحث يتتمي إلى فئة البحوث التطويرية في تكنولوجيا التعليم، فقد استخدم

$$
\text { الباحث المناهج الثلاثة الآتية بشكل متتابع: }
$$

ا ـ المنهج الوصفي: واستخدمه الباحث في مرحلة الدراسة والتحليل.

r. ـ منهج تطوير المنظومات التعليمية: واستخدمه الباحث في تصميم وتطوير الفيديو الرقمي القائم علن السرد القصصي في بيئة التعلم الإلكتروني.

r. المنهج شبة التجريبي: واستخدمه الباحث في قياس أثر استخدام الفيديو الرقمي القائم على

\section{http://dx.doi.org/10.29009/ijres.5.1.8}


السرد القصصي في بيئة التعلم الإلكتروني في تنمية الدافعية العقلية والتحصيل الأكاديمي لدن

$$
\text { طلاب كلية التربية بجامعة الملك سعود. }
$$

$$
\text { متغيرات البحث }
$$

أ- المتغير المستقل: الفيديو الرقمي القائم علن السرد القصصي في بيئة التعلم الإلكتروني.

$$
\text { ب- المتغيرات التابعة: الدافعية العقلية، والتحصيل الأكاديمي. }
$$

$$
\text { التصميم التجريبي }
$$

\begin{tabular}{|c|c|c|c|}
\hline القياس البعدي & المعالجة التجريبية & القياس القبلي & المجموعة \\
\hline \multirow[t]{2}{*}{ 1 - م- الاخياس الدافعية العقلية } & الفيديو الرقمي القائم علن السرد القصصي في بيئة التعلم & \multirow[t]{2}{*}{ 1- ا- مقياس الدافعية العقلية } & التجريبية \\
\hline & الطريقة التقليدية & & الضابطة \\
\hline
\end{tabular}

يستخدم البحث الحلاي تصميم المجموعة التجريبية، والمجموعة الضابطة (Y X )، كما يتضح

في الجدول (1) - (1) - (1)

$$
\text { جدول (1) - التصميم التجريبي للبحث }
$$

\section{فروض البحث}

1. يوجد فرق ذو دلالة إحصائية عند مستوى (0 · , ·) بين متوسطي درجات المجموعة التجريبية التي استخدمت الفيديو الرقمي القائم على السرد القصصي، والمجموعة الضابطة التي درست باستخدام الطريقة التقليدية، في التطبيق البعدي للاختبار التحصيلي لصالح المجموعة التجريبية. r. يوجد فرق ذو دلالة إحصائية عند مستوى (0 · , •) بين متوسطي درجات المجموعة التجريبية التي استخدمت الفيديو الرقمي القائم علن السرد القصصي، والمجموعة الضابطة 
التي درست باستخدام الطريقة التقليدية، في التطبيق البعدي لمقياس الدافعية العقلية لصالح

المجموعة التجريبية.

$$
\text { أدوات البحث }
$$

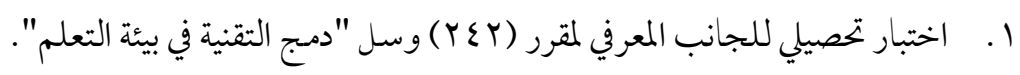
r. ب. مقياس الدافعية العقلية. مصطلحات البحث

\section{الفيديو الرقمي Digital Video}

يعرف إسكندر، وإبراهيم (1) • ( ) الفيديو الرقمي بأنه "صور متحركة تم تسجيلها من خلال

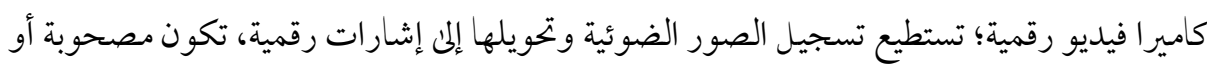

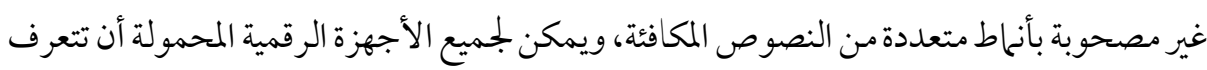
عليها". (ص.ع (7)

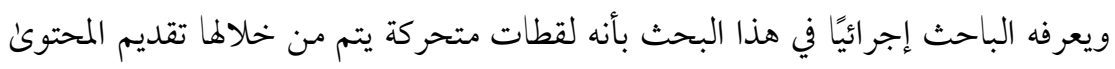

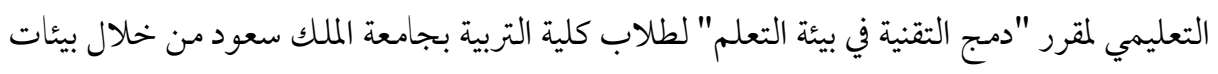
تعلم إلكترونية.

السرد القصصي Storytelling يعرف هزازي، والفراني (·r.r. السرد القصصي بأنه "تحويل القصص الورقية المطبوعة

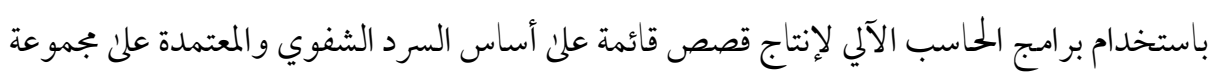

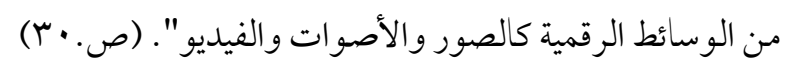

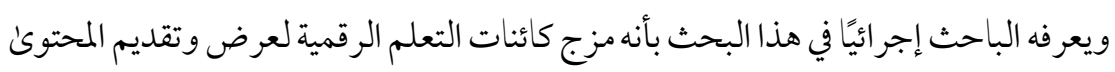

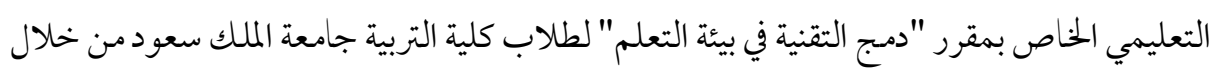
الفيديو الرقمي معتمداً علن نمط القصة أو الرواية.

http://dx.doi.org/10.29009/ijres.5.1.8 


\section{Mental Motivation الدافعية العقلية}

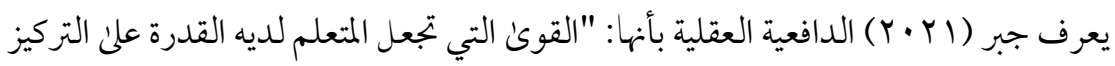
وتعلم الأشياء الجلديدة والمفيدة، التي تتطلب تحدياً لقدر اته، والبناء علن أفكار وآراء الآخرين، و كذلك

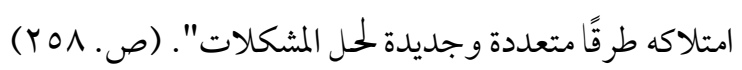
ويعرفها الباحث إجرائيًا في هذا البحث بأنها قدرة طلاب كلية التربية بجامعة الملك سعود علن الن إنتاج كثيراً من الأفكار المتنوعة في مقرر "دمج التقنية في بيئة التعلم" وتقاس بالدرجة التي يكصل عليها الطلاب علن مقياس الدافعية العقلية بأبعاده المتمثلة في: التكامل المعرفي، التركيز العقلي، التوجه نحو التعلم، و الحل الإبداعي للمشكلات.

\section{التحصيل الأكاديمي Academic Achievement}

يعرف التحصيل الأكاديمي بأنه مدئ استيعاب الطلاب لما تعلموه من خبرات معينة في موضوع معين وذلك قياساً بالدرجات التي يجصلون عليها في اختباراتهم في المواد الدراسية. (أمد، $(r \cdot 19$

ويعرفه الباحث إجرائًا في هذا البحث بأنه مدى استيعاب طلاب كلية التربية بجامعة الملك

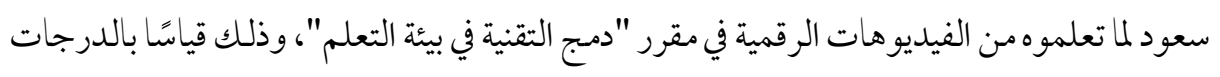
التي يحصلون عليها في الاختبار النهائي لهذا المقرر. منهج البحث وإجراءاته

أولاً: تحديد قائمة معايير تصميم الفيديو الرقمي القائم على السرد القصصي في بيئة تعلم إلكترونية على تملى تنمية الدافعية العقلية والتحصيل الأكاديمي لدى طلاب كلية التربية بجامعة الملك سعود.، ويأتي هذا الإجر اء في إطار الإجابة عن السؤال الأول والذي ينص علن: "ما معايير تصميم الفيديو الرقمي القائم علن السرد القصصي في بيئة تعلم إلكترونية علن تنمية الدافعية العقلية والتحصيل الأكاديمي لدنئ طلاب كلية التربية بجامعة الملك سعود؟".، وجاءت خطوات وإجراءات إعداد القائمة موضحة علن النحو 
هدف القائمة: هدفت القائمة إلى التوصل للمعايير الفنية والتربوية المرتبطة بتصميم الفيديو الرقمي القائم علئ السرد القصصي في إطار بيئة تعلم إلكترونية على تنمية الدافعية العقلية والتحصيل الأكاديمي لدئ طلاب كلية التربية بجامعة الملك سعود. ب- إعداد القائمة المعايير: اعتمد الباحث علإ عديد من الأدبيات والمراجع المتعلقة بموضوعات التعلم في تصميم الفيديو الرقمي القائم علن السرد القصصي في إطار بيئة تعلم إلكترونية

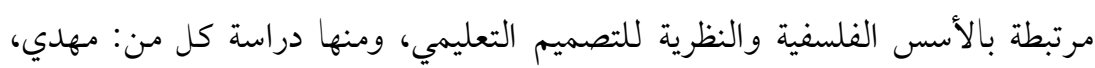

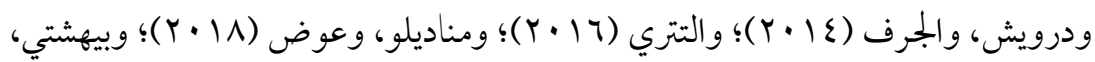
وآخرون (Beheshti, et al., 2018) وتكونت قائمة المعايير في صورتها الأولية من (9) معايير

$$
\text { رئيسية، و (عV) مؤشراً. }
$$

صدق قائمة المعايير . تم عرض قائمة المعايير في صورتها الأولية علن مجموعة من السادة الخبراء و المتخصصين في مجال تكنولوجيا التعليم، لإبداء آرائهم حول سلامة الصياغة اللغوية، والدقة العلمية لبنود القائمة، ومدىئ أهمية المؤشرات للمعايير الرئيسية للقائمة، وملاءمتها لبيئات التعلم الإلكترونية، وكذلك مدىن انتحاء المؤشرات للمعايير الرئيسية، وملاءمتها لبيئات التعلم الإلكترونية، وإضافة أو حذف أو تعديل ما يرونه مناسبًا، وإبداء أي ملاحظات أو مقترحات أخرىن، وقد أبدئ المحكمون بعض المقترحات التي تمثلت في تعديل الصياغة اللغوية لبعض المعايير، إعادة ترتيب بعض المعايير الفرعية، وحذف بعض الكلمات المكررة في صياغة بعض المعاير، وقد قام الباحث بإجراء كل التعديلات المطلوبة.، وقد بلغ صدق

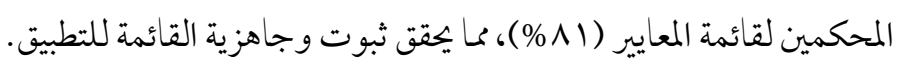
د- قائمة المعايير في صورتها النهائية. بعد إجراء كافة التعديلات التي طلبها المحكمون، اشتملت

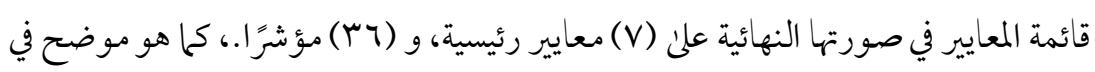

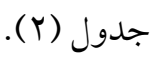

\section{http://dx.doi.org/10.29009/ijres.5.1.8}




\begin{tabular}{|c|c|c|}
\hline عدد المؤشرات & المعايير الرئيسية & b \\
\hline$\varepsilon$ & الأهداف التعليمية & 1 \\
\hline 。 & المقدمة & r \\
\hline 1 & المحتوئ التعليمي & r \\
\hline$\varepsilon$ & الأنشطة التعليمية & $\varepsilon$ \\
\hline ir & عناصر الوسائط المتعددة & 0 \\
\hline r & التقويم & 1 \\
\hline r & التوثيق العلمي & $\checkmark$ \\
\hline r & $\checkmark$ & لجموع \\
\hline
\end{tabular}

ثانيًا: التصميم التعليمي للفيديو الرقمي القائم على السرد القصصي في التعلم الإلكتروني لتنمية الدافعية

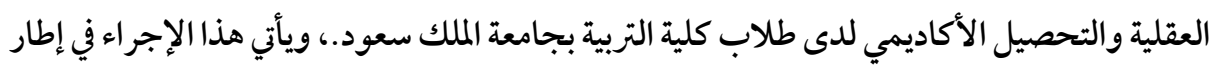
الإجابة عن السؤال الثاني، والذي ينص علن: "ما التصميم التعليمي لبيئة تعلم إلكترونية في توظيف

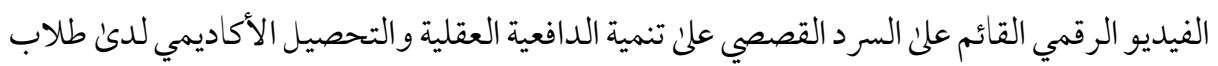

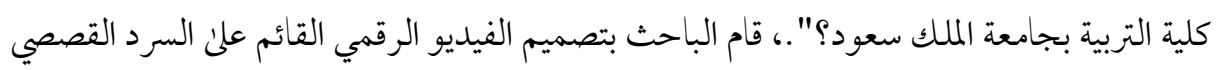
في بيئة تعلم إلكترونية باتباع مراحل التصميم التعليمي للنموذج العام للتصميم التعليمي (ADDIE)

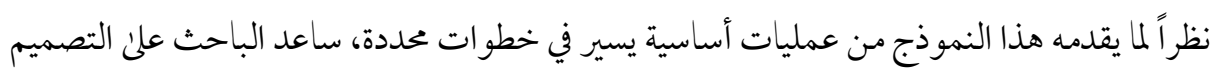

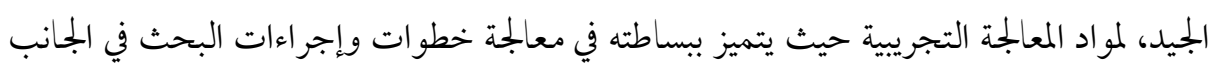

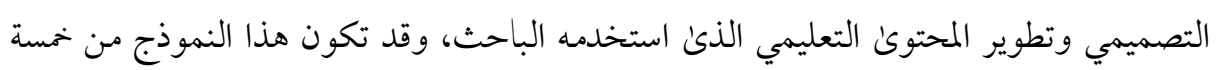

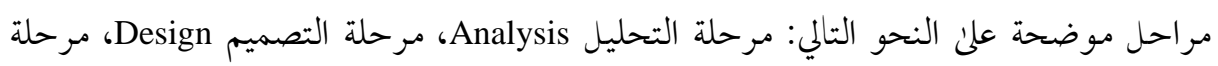

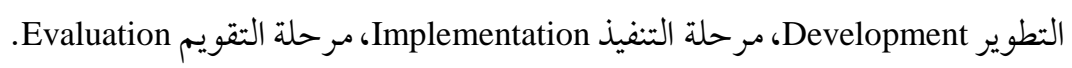
مرحلة التحليل Analysis: - اشتملت هذه المرحلة على الآتي:

أ. تحديد المدف العام: يتحدد الهدف العام في تنمية الدافعية العقلية والتحصيل الأكاديمي في مقرر (Y Y Y وسل) "دمج التقنية في بيئة التعلم" لدى طلاب كلية التربية جامعة الملك سعود 
في إطار قياس أثر تصميم الفيديو الرقمي القائم علن السرد القصصي في بيئة تعلم إلكترونية. ب. تحليل المثكلة وتقدير الحاجات التعليمية: من خلال ما تم التوصل إليه في الإحساس وتحديد مشكلة البحث الحلي التي تبلورت في الحاجة نحو تنمية الدافعية العقلية والتحصيل الأكاديمي لمقرر "دمج التقنية في بيئة التعلم" لدىن طلاب كلية التربية بجامعة الملك سعود، من خلال تصميم وانتاج فيديوهات رقمية قائمة علن السرد القصصي في بيئة تعلم إلكترونية وهو مـا يهدف إليه البحث الحالي في سياق معالجة البحث وإجراءات وخطوات الإجابة على أسئلته وفق الإجراءات والخطو ات التي اتبعها الباحث.

تحديد خصائص المتعلمين: تم التعرف علن خصائص طلاب كلية التربية بجامعة الملك سعود ? في مقرر "دمج التقنية في بيئة التعلم" حيث أنهم طلاب المستوئ الثاني في الكلية والذين يتسمون بصفات شخصية واهتحمات متقاربة ولديهم القدرة علن استخدام المستحدثات التكنولوجية ولهم إلمام بمهار ات التعامل مع الحاسب الآلي والإنترنت، كما أنهم يمتلكون الأجهزة اللوحية و النقالة ويستطيعون التعامل معها ولديهم القدرة على الاتصال والتو اصل من خلالها. د. تحديد المهات التعليمية والمحتوى التعليمي: تم تحديد مجموعة من المهام التعليمية لطلاب عينة البحث؛ بحيث يقوموا بها أثناء تعلمهم من خلال تصميم الفيديو الرقمي القائم على السرد القصصي داخل بيئة تعلم إلكترونية، مع إعطاء قياسات محددة لكل مهمة بهدف تنمية الدافعية العقلية والتحصيل الأكاديمي لديهم.

ه. تحليل المواردوالقيود في البيئة التعليمية: تم التأكدمن قبل الباحث قبل البدء في تصميم واجراء المعالجات التجريبية من توفر المتطلبات اللازمة لعمليات سير اجر اء البحث الحلالي حيث تم تحليل الإمكانات التي تساعد الباحث في تطبيق التجربة مثل توفير المكان المخصص بالتطبيق وهو معمل الحاسب الآلي رقم (ع 1 ) بكلية التربية بجامعة الملك سعود، وتوافر البرامج اللازمة لإنتاج الفيديوهات الرقمية، كما تم التأكد من مدئ مناسبة الموارد والأجهزة وعددها 
ونقاط الاتصال بالإنترنت لتكون بيئة تعليمية مناسبة لتعلم الطلاب مع توفير الوقت اللازم

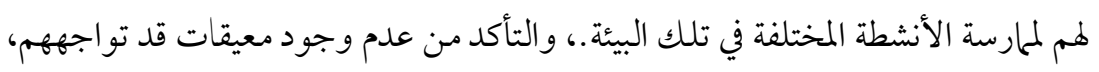
وكذلك توفير الدعم الإداري والتشجيع المعنوي من خلال المو افقات الإدارية التي تعد من متطلبات إجراء البحث الحلالي.

مرحلة التصميم Design، وشملت هذه المرحلة الخطو ات الآتية:

أ. ت تحديد الأهداف التعليمية: تمصياغة قائمة بالأهداف التعليمية وذلك في ضوء تنمية الدافعية

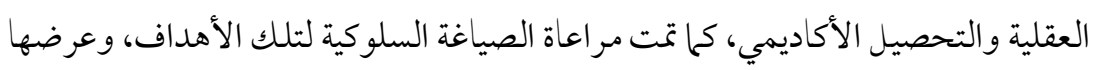
علن مجموعة من المحكمين في مجال تقنيات التعليم؛ للتأكد من صدقها، ومناسبتها، ووضوحها، وقد أشار المحكمون إلى بعض التعديلات من حيث الصياغة وتم إجراء

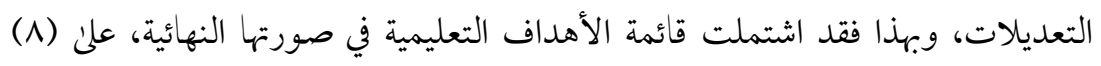

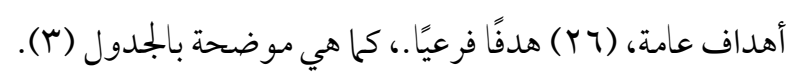
جدول (r) الأهداف التعليمية لمقرر Y Y Y وسل (دمج التقنية في بيئة التعلم)

\begin{tabular}{|c|c|c|}
\hline الأهداف الفرعية & المدف العام & الموضوع الرئيس \\
\hline 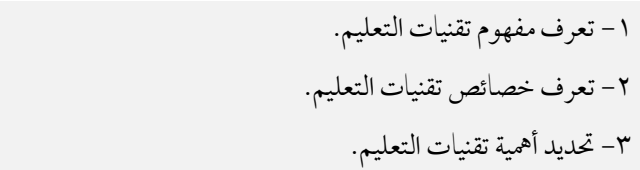 & ت ا- تعنوف مجاهية التعليم. وخصائص & مقدمة في تقنيات \\
\hline هـ - ـ - تعرظف آليات استخدام التقنيات في بيئة التعليم والتعلم. & 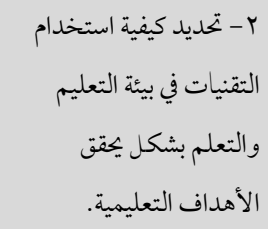 & بيئة التعليم والتعلم التقنيات في \\
\hline 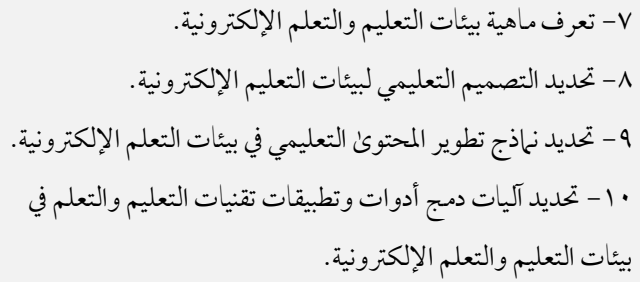 & و بـ الوميم وإنتاج بيئات التعليم التهية & بيئات التعليم والتعلم \\
\hline
\end{tabular}

\section{http://dx.doi.org/10.29009/ijres.5.1.8}


Volume (5) No. (1) 2022

\begin{tabular}{|c|c|c|}
\hline الأهداف الفرعية & المدف العام & الموضوع الرئيس \\
\hline 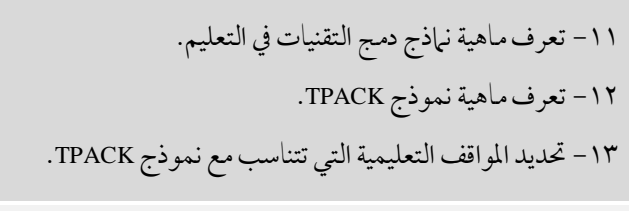 & $\begin{array}{r}\text { ع - توظيف نموذج } \\
\text { التعليمية. }\end{array}$ & $\begin{array}{l}\text { دمسج التقنيات فية التعليمية } \\
\text { استخدام نموذج } \\
\text { TPACK }\end{array}$ \\
\hline 1 1 1 - - توظيف نموذج TPACK 1 - توظيف نموذج TPACK في تطوير المحتوئ. & 0 - تمديد أطر العملية & $\begin{array}{c}\text { توظيف نموذج } \\
\text { TPACK }\end{array}$ \\
\hline 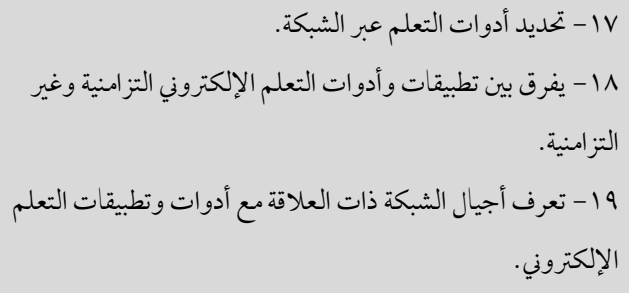 & الإلـ - تعرف تطبيقات وأدوات & تطبيقات و أدوات التعليم و التعلم \\
\hline 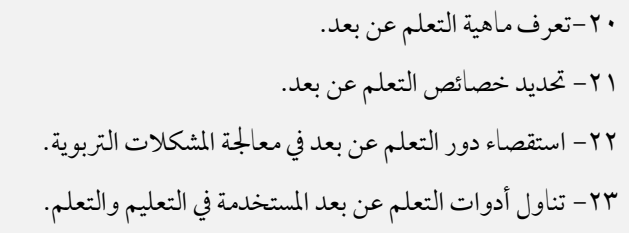 & لع لعد في العملية التعليمية. أهمية التعلم عن & التعلم عن بعد \\
\hline 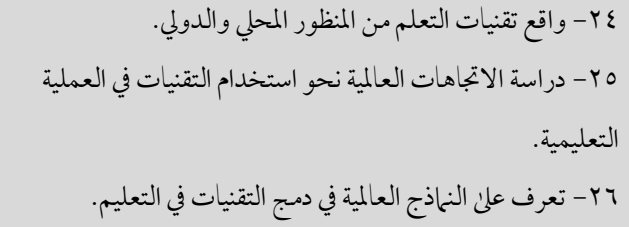 & 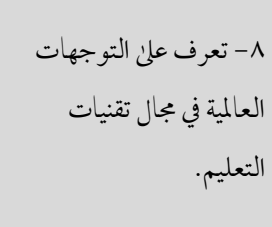 & قضايا واتجاهات \\
\hline
\end{tabular}

ب. تنظيم المحتوى التعليمي: في ضوء الأهداف التي تم تحديدها سابقًا قام الباحث باستخلاص المحتوى التعليمي المتعلق بالأهداف ليشمل موضوعات التعلم المرتبطة بمقرر "دمـج التقنية في بيئة التعلم"، وكذلك الأنشطة والمهام التعليمية المرتبطة بها، و التقييمات المناسبة في ضوء المحتوى التعليمي المرتبط بمقرر "دمسج التقنية في بيئة التعلم" والذي تم معالجته في تصميم فيديوهات رقمية باستخدام أسلوب السرد القصصي، ولضمان صدق وتماسك المحتوىن التعليمي، عرض الباحث المحتوى التعليمي على جمموعة من المحكمين المتخصصين، بهدف طرح آرائهم حول مدىن ارتباط المحتوى التعليمي بالأهداف، ومدىن كفايته وملائمته

\section{http://dx.doi.org/10.29009/ijres.5.1.8}


لتحقيقها، واتفق المحكمون علن صلاحيته مع تعديل بعض الأجزاء في إعادة الصياغة والتي قام الباحث بتعديلها، وبذلك أصبحت مادة المحتوى التعليمي صالحة للتقديم في بيئة التعلم إلكترونية.

تحديد طرق تقديم المحتوى التعليمي: تم تقديم المحتوى التعليمي من خلال أنماط المعالجة التجريبية المتمثلة في تصميم فيديوهات رقمية باستخدام أسلوب السرد القصصي لمقر ر "دمج التقنية في بيئة التعلم" وتم استخدام مادة المعالجة التجريبية في بيئة تعلم إلكترونية، وذلك في سياق تحقيق هدف البحث الحالي وهو تنمية الدافعية العقلية والتحصيل الأكاديمي لطلاب مقرر "دمسج التقنية في بيئة التعلم".

د. تصميم الأنشطة التعليمية: قام الباحث بتصميم عدد من الأنشطة التعليمية في ضوء موضوعات التعلم التي تم استخلاصها من خلال تحليل المحتوى التعليمي المرتبط بموضوعات التعلم في مقرر (Y Y و وسل) "دم-ج التقنية في بيئة التعلم"، واستخدم الباحث عددمن البرامج التي تستخدم في إنتاج الأنشطة، وتم صياغتها في صورة إلكترونية باستخدام برنامج Quiz Maker، وبرنامج Course Lab وتأتي هذه الأنشطة في ضوء الموضوعات

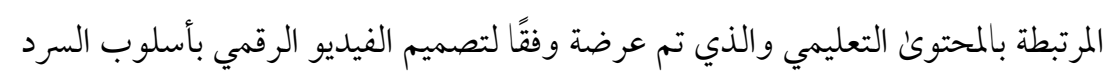
القصصي. ه- تصميم أدوات القياس محكية المرجع: استخدم الباحث في البحث الحلالي أداتين للقياس هما مقياس الدافعية العقلية الخاص بمقياس كاليفورنيا والذي أعده وبناه في صورته الأصلية جيانكارلو، فاشيون (Giancarlo, \& Facione, 1998)، حيث تكون المقياس في صورته الأصلية من (VY) فقرة، وقد تم تطوير هذا المقياس وتعريبه علن البيئة الأردنية من قبل فيل

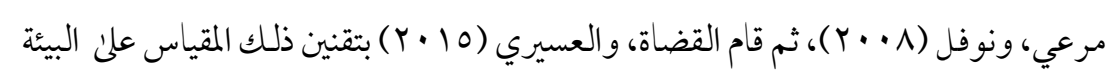
السعودية، وأصبح المقياس في صورته النهائية مكونا من (ع) (7) فقرة، كما استخدم الباحث

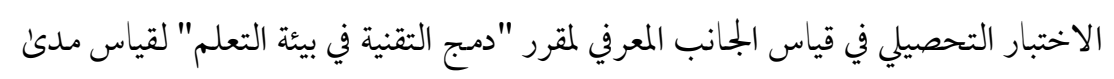


تحصيل الطلاب المتتظمين دراسياً في كلية التربية بجامعة الملك سعود في الموضوعات محل البحث، وذلك قبل ويعد تدريس الطلاب باستخدام الفيديو الرقمي القائم على السرد القصصي؛ للتعرف على مدى تحقيق الطلاب للأهداف للجانب المعرفي في ذلك المقرر، وسيتم تناول إعداد الاختبار التحصيلي تفصيليًا في الجزء الخاص بأدوات البحث.

\section{Development مرحلة التطوير}

ارتبطت هذه المرحلة بتطوير المحتون التعليمي في تصميم فيديوهات رقمية بأسلوب السرد القصي في بيئة تعلم إلكترونية، وتم إعداد المحتوى التعليمي المرتبط بالتحصيل الأكاديمي والأنشطة والمهام التي تراعئ تنمية الدافعية العقلية لدئ أفراد عينة البحث الحلالي، وجاء المحتوئ التعليمي في ضوء تحليل المحتوى لمقرر Y \& Y وسل "دمج التقنية في بيئة التعلم"، والذي يدرس في المستوى الثاني لطلاب كلية التربية بجامعة الملك سعود، وبناءً عليه تم ضبط أدوات وأنشطة التعلم المصاحبة للفيديوهات الرقمية بأسلوب السرد القصصي، والتي تمثلت عناصرها في النصوص المكتوبة، الصوت، الصور، والرسوم المتحركة، والرسوم ثلاثية الأبعاد، والتي تم عرضها في بيئة نظام إدارة التعلم Blackboard ، واستخدام الباحث العديد من البرامج والتطبيقات المساندة في إنتاج الفيديوهات Adobe Adobe Photoshop وذلك لإنتاج الصور الثابتة، واستخدم برنامج: برنامج Animate لإنتاج الرسوم المتحركة، برنامج Camtasia Studio وذلك لإنتاج الفيديوهات التعليمية، برنامج Articulate Storyline لإنتاج بعض المحتوكئ التفاعلي والاختبارات والأنشطة الإلكترونية. مرحلة التنفيذ Implementation، وقد اشتملت علي: تجهيز موضوعات المقرر، حيث قام الباحث بتحديد الموضوعات الرئيسية والفرعية الحاصة بمحتوى المقرر ورفعها علن نظام إدارة التعلم وتوزيعها على تسعة أسابيع دراسية شكل (1)، كما تم إجراء التجربة الاستطلاعية في إطار تصميم الفيديو الرقمي القائم على السرد القصصي في بيئة تعلم إلكترونية؛ وقام الباحث بتطبيق التجربة علن بجموعة من الطلاب أفر اد العينة الاستطلاعية؛ للتأكد من سهولة ظهور المحتوئ التعليمي، ووضوح التعليات، وفتح جميع الروابط والأشطة التعليمية، وعمل 
التقويم النهائي للمقرر بالشكل الصحيح، والوقوف علن المشكلات التي من الممكن أن تواجه الطلاب أفراد العينة الرئيسية عند استخدام التجربة الأساسية، وقد اتضح عدم وجود صعوبات في ظهور المحتوكن ، وسهولة تصفح الأنشطة بشكل متسلسل وسريع، واستخدام عناصره، بالإضافة إلى وضوح وسهولة استخدام الفيديوهات الرقمية القائمة على السرد القصصي، بعد ذلك تم التطبيق الفعلي للتجربة الأساسية للبحث على طلاب المجموعة التجريبية.

شكل رقم ( ) المحتوئ التعليمي من خلال بيئة التعلم الإلكتروني Blackboard

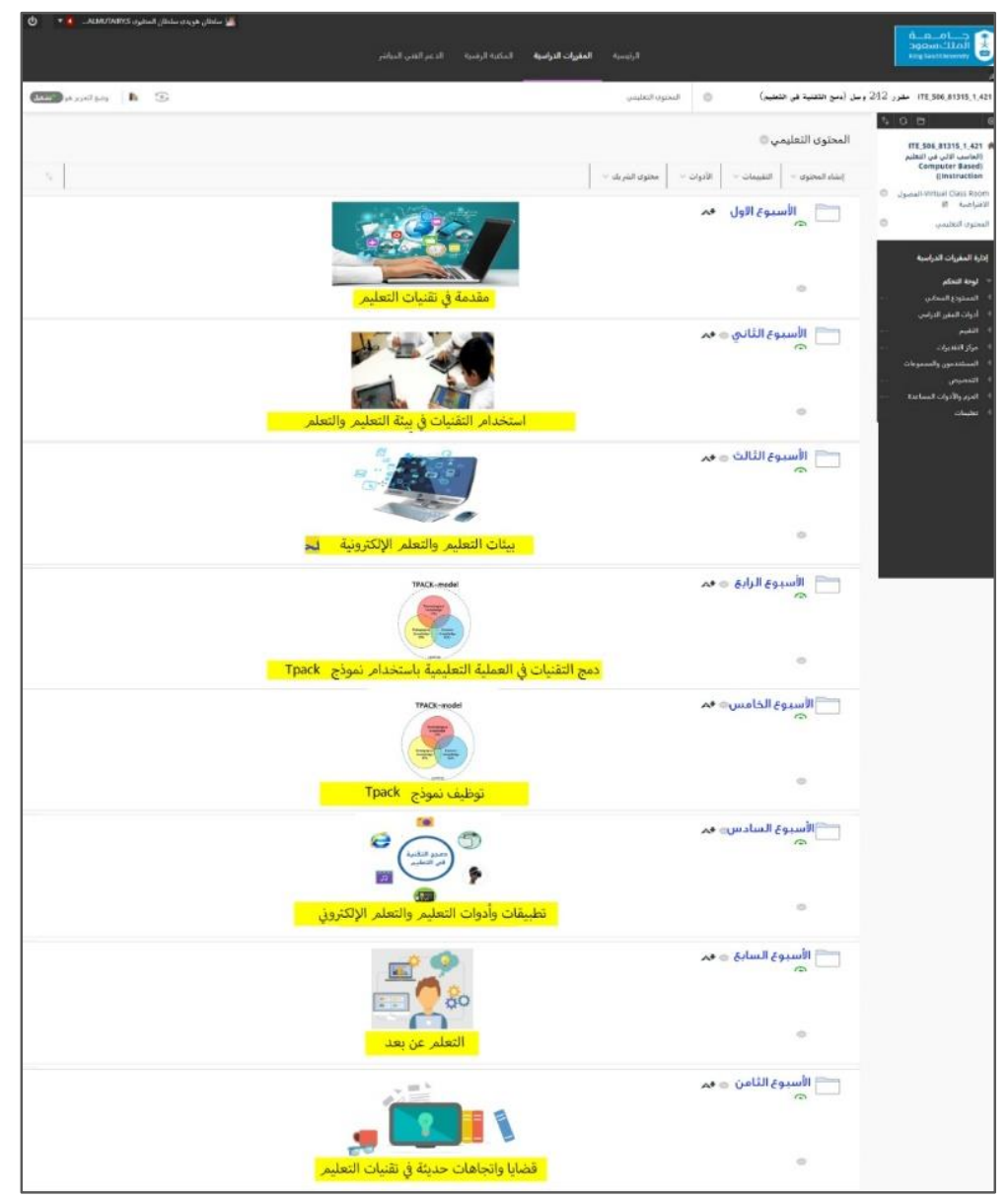

http://dx.doi.org/10.29009/ijres.5.1.8 


\section{Evaluation مرحلة التقويم}

ارتكزت هذه المرحلة علن عدد من الخطو ات وهي: التقويم البنائي للنسخة الأولية؛ حيث تم

عرض بيئة التعلم الإلكترونية المستخدمة لتصميات الفيديو الرقمية بأسلوب السرد القصصي لمقرر "دمج التقنية في بيئة التعلم" علن بجموعة من المحكمين للتأكد من صلاحيتها للتطبيق.، كحا تم إجراء التعديلات والإخراج النهائي لبيئة التعلم الإلكترونية في ضوء نتائج التقويم التكويني، ومن خلال ملاحظات المحكمين، تم إجراء التعديلات التي أشاروا إليها، وجاء التقويم الختامي في التطبيق البعدي للاختبار التحصيلي، ومقياس الدافعية العقلية. ثالثًا: إعداد أدوات البحث: شملت أدوات البحث على الآتي أ. مقياس الدافعية العقلية بعد الاطلاع علن الأدبيات التربوية والبحوث والدراسات السابقة التي تناولت موضوع الدافعية العقلية، استخدم الباحث مقياس الدافعية العقلية الخاص بمقياس كاليفورنيا والذي أعده وبناه في صورته الأصلية جيانكارلو وفاشيون (Giancarlo, \& Facione, 1998)، حيث تكون المقياس في صورته الأصلية من (VY) فقرة، وقد تم تطوير هذا المقياس وتعريبه علن البيئة الأردنية من قبل

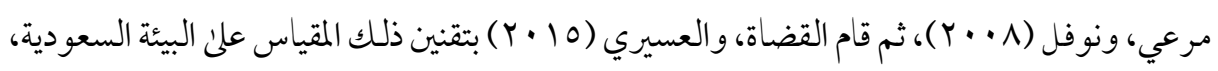

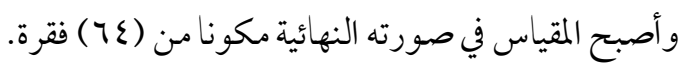

\section{1- الهدف من مقياس الدافعية العقلية}

يهدف المقياس إلى قياس الدافعية العقلية لدئ طلاب كلية التربية بجامعة الملك سعود، ويتكون المقياس من (عا) فقرة تقيس الجوانب المختلفة للدافعية العقلية، ويقاس التقدير بمقياس ليكرت الرباعي الذي يتكون من أربع استجابات وهي (موافق علن الإطلاق، مو افق إلى حدما، غير موافق إلى لئ حد ما، غير موافق على الإطلاق)، وتعطى الدرجات (ع- () لكل استجابة موجبة علن التوالي، والدرجة الكلية على المقياس تمثل درجة الدافعية العقلية للتعلم للطالب. 


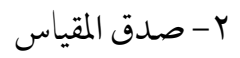

قام القضاة، والعسيري (10 · ب) بالتحقق من الصدق الظاهري للمقياس من خلال عرضه علن مجموعة من أعضاء هيئة التدريس تخصص علم النفس التربوي والقياس والتقويم في جامعة الملك سعود، واقترحوا بعض التعديلات اللغوية علن بعض المفردات، وصياغة بعض العبارات بحيث تتناسب مع البيئة السعودية، بالإضافة إلى ذلك تم التحقق من صدق البناء للمقياس، وذلك بتطبيقه

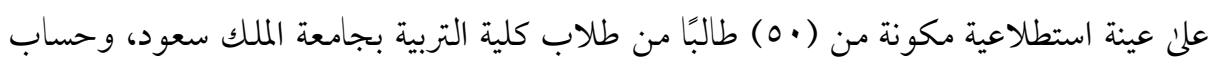

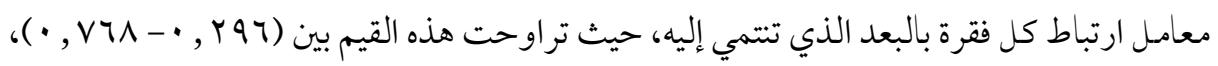
كما تم حساب معامل ارتباط كل بعد بالبعد الآخر، وبدرجة المقياس الكلية، حيث تراوحت هذه القيم

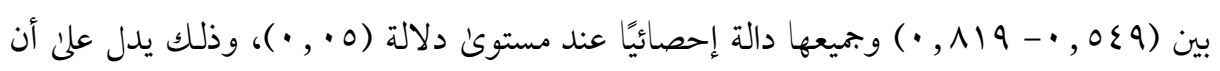
المقياس يتمتع بدرجة معقولة من صدق البناء وصالح للتطبيق علن عينة البحث. r - ثبات المقياس

قام القضاة، والعسيري (10 ( ب ) بالتحقق من ثبات المقياس باستخدام معامل الثبات بطريقة (كرونباخ- ألفا)، وقد تبين أن معامل الاتساق الداخلي للمقياس يتراوح للأبعاد ما بين (V0, •-ـ

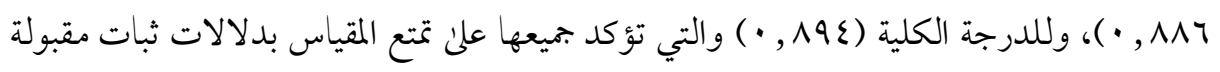

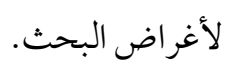

\section{ب. الاختبار التحصيلي للجانب المعرفي لمقرر "دمج التقنية في بيئة التعلم". وقد مرّ إعداد هذا الاختبار بالخطو ات الآتية:}

1 - تحديد الهدف من الاختبار التحصيلي يتمثل الهدف من الاختبار التحصيلي للجانب المعرفي لمقرر "دمسج التقنية في بيئة التعلم" لقياس

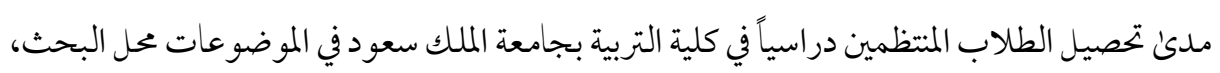
وذلك قبل وبعد تدريس الطلاب باستخدام الفيديو الرقمي القائم علن السرد القصصي؛ للتعرف علن مدى تحقيق الطلاب للأهداف للجانب المعرفي لدمج التقنية في بيئة التعلم. http://dx.doi.org/10.29009/ijres.5.1.8 


$$
\begin{aligned}
& \text { ץ- تحديد الموضوعات التي تضمنها الاختبار التحصيلي: } \\
& \text { ففي ضوء الهدف من الاختبار، والمحتوىن، تم تحديد الموضوعات الأتية: } \\
& \text { - مقدمة في تقنيات التعليم. } \\
& \text { - } \\
& \text { - - بيئات التعليم والتعلم الإلكترونية. } \\
& \text { - دمج التقنيات في العملية التعليمية باستخدام نموذج TPACK. }
\end{aligned}
$$

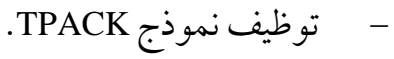

$$
\begin{aligned}
& \text { - - تطبيقات وأدوات التعليم والتعلم الإلكتروني. }
\end{aligned}
$$

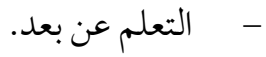

$$
\begin{aligned}
& \text { - قضايا واتجاهات حديثة في تقنيات التعليم. } \\
& \text { r- وضع نظام تقدير الدرجات للاختبار التحصيلي }
\end{aligned}
$$

تم استخدام التقدير الكمي للاختبار التحصيلي كالتالي: اشتمل على (•ع) سؤالاً من نوع

الاختيار من متعدد، وتجمع الدرجات، ثم تحسب الدرجة الكلية لكل طالب من طلاب كلية التربية، ومن خلالها يتم الحكم على تحصيله فيما يتعلق بالجو انب المعرفية.

$$
\text { ع - إعداد تعليمات الاختبار التحصيلي }
$$

وقد حرص الباحث علن أن تكون تعليات الاختبار التحصيلي واضحة ومحددة في الصفحة الأولى للاختبار التحصيل، وتشمل علن توجيهات لطلاب كلية التربية إلى قراءة المحتويات، والتعرف عن الأسئلة المستخدمة، وكيفية الإجابة عنها. 


$$
\text { 0- - حساب ثبات الاختبار التحصيلي }
$$

وللتحقق من ثبات الاختبار التحصيلي للجانب المعرفي لمقرر "دمج التقنية في بيئة التعلم"

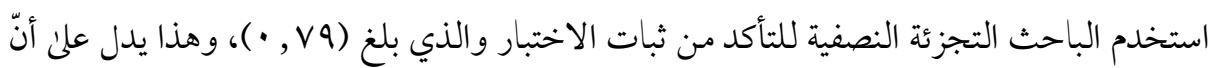
الاختبار التحصيلي للجانب المعرفي لمقرر "دمج التقنية في بيئة التعلم" يتمتع بدرجة مناسبة من الثبات يمكن الاعتماد عليها في التطبيق الميداني للبحث.

رابعًا: إجراء تجربة البحث

في هذه المرحلة نفذت تجربة البحث بعد الانتهاء من إعداد الاختبار التحصيلي ومقياس الدافعية العقلية وعرضها علن المحكمين والتأكد من صدقها وثباتها، وتم إجراء تجربة البحث علن حسب

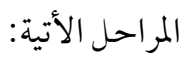

ا. اختيار عينة البحث: تم اختيار عينة البحث من طلاب كلية التربية جامعة الملك سعود في مقرر Y Y و وسل "دمسج التقنية في بيئة التعلم" وبلغ العدد الإجمالي للعينة (rا7) طالباً، تم تقسميهم إلى مجموعتين وفقًا للتصميم التجريبي للبحث، المجموعة التجريبية تدرس باستخدام الفيديو الرقمي القائم علئ السرد القصصي وبلغ عدد هذه المجموعة (• ب) طالباً، والمجموعة الضابطة تدرس باستخدام الطريقة الاعتيادية، وبلغ عدد هذه المجموعة (Yr) طالباً.

r. القياس القبلي: تم تطبيق أدوات البحث المتمثلة في الاختبار التحصيلي ومقياس الدافعية العقلية على المجموعتين تطبيقاً قبلياً، حيث تم رصد درجاتهم تمهيداً لإجراء المعالجة المبحة

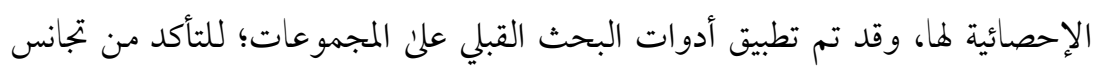
مجموعات عينة البحث.

r. أثناء التجربة: قامت المجموعة التجريبة بدراسة الموضوعات باستخدام فيديوهات رقمية قائمة علن السرد القصصي في بيئة تعلم إلكترونية من خلال نظام إدارة التعلم الإلكتروني

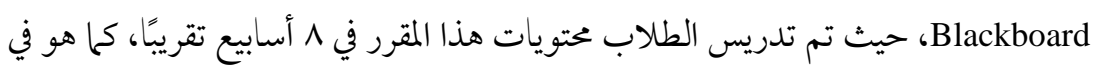


الجددول (r) الذي يوضح عدد المحاضرات وعنوانها وأهداف كل محاضرة، وأيضا تم استخدام المتتدئ التعليمي في نظام إدارة التعلم Blackboard لتقديم بعض الأنشطة التعليمية والتباحث حول موضوعات المحتون التعليمي لكل محاضرة، حيث تكونت بيئة التعلم الإلكتروني المستخدمة في التجربة تكونت من ثلاث عناصر وهي: ( (1) فيديوهات رقمية قائمة على السرد القصصي، (Y) ملفات pdf، (Y) المنتدئ التعليمي.

\section{حساب تكافؤ المجموعات} تم حساب تكافؤ المجموعات من خلال التطبيق القبلي لأدوات البحث كالآتي: أ. أ مقياس الدافعية العقلية

قام الباحث بالتأكد من تكافؤ المجموعات باستخدام اختبار (ت) لعينتين مستقلتين Independent samples t test مقياس الدافعية العقلية القبلي علن المجموعتين (التجريبية والضابطة)، والجدول (ع) يوضح ذلك. جدول (ع) دلالة الفروق بين القياسين القبليين للمجموعتين الضابطة والتجريبية في درجات مقياس الدافعية العقلية.

\begin{tabular}{|c|c|c|c|c|c|c|}
\hline قلديمة & درجة الحرية & قيمة (ت) & الالنحراف & المتوسط & العدد & المجموعة \\
\hline \multirow[b]{2}{*}{$\cdot, 7 \leqslant \wedge$} & \multirow[b]{2}{*}{7.} & \multirow[b]{2}{*}{$\cdot, \varepsilon \circ \wedge$} & $\backslash \wedge, \S \vee$ & $10 \varepsilon, 9 V$ & $r$. & التجريبية \\
\hline & & & $17, r 1$ & lor, $9 \varepsilon$ & ru & الضابطة \\
\hline
\end{tabular}

$$
\text { ( ) }
$$

يتضح من جدول (ع) أن قيمة (ت) بلغت (ع ع , • ) ) وجاءت بمستوى دلالة أكبر من (0 • , • )، وتشير هذه النتيجة إلى عدم وجود فروق دالة إحصائياً بين القياسين القبليين للمجموعتين الضابطة والتجريبية في مقياس الدافعية العقلية قيد البحث، وهذا يشير إلى أن المجموعتين متجانستين (متكافئتين) وبالتالي صلاحيتها لتطبيق التجربة. 


$$
\text { ب. ب. الاختبار التحصيلي }
$$

قام الباحث بالتأكد من تكافؤ المجموعات باستخدام اختبار (ت) لعينتين مستقلتين Independent samples t test الاختبار التحصيلي القبلي علن المجموعتين (التجريبية والضابطة) والجدول (0) يوضح ذلك. جدول (0) دلالة الفروق بين القياسين القبليين للمجموعتين الضابطة والتجريبية في درجات الاختبار التحصيلي

\begin{tabular}{|c|c|c|c|c|c|c|c|}
\hline قالدلالة & درجة الحرية & قيمة (ت) & الالنحراف & المتوسط & العدد & المججموعة & \\
\hline \multirow{2}{*}{$\cdot, 7 / V$} & \multirow{2}{*}{7.} & \multirow{2}{*}{$\cdot, 0 . r$} & $r, r \varepsilon$ & $1 \cdot, r V$ & $r$. & التجريبية & الاختبار \\
\hline & & & $r, \wedge q$ & $৭, \wedge \wedge$ & rr & الضابطة & جصيلي \\
\hline
\end{tabular}

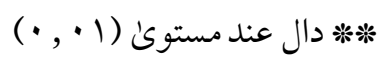

يتضح من جدول (0) أن قيمة (ت) بلغت (ب.0 , •) وجاءت بمستوى دلالة أكبر من (0 • , • )، وتشير هذه النتيجة إلى عدم وجود فروق دالة إحصائياً بين القياسين القبليين للمجموعتين الضابطة والتجريبية في درجات الاختبار التحصيلي قيد البحث، وهذا يشير إلى أن المجموعتين متجانستين (متكافئتين) وبالتالي صلاحيتها) لتطبيق التجربة.

ع- القياس البعدي: بعد دراسة البرنامج قام الباحث بالتطبيق البعدي لأدوات البحث المتمثلة في

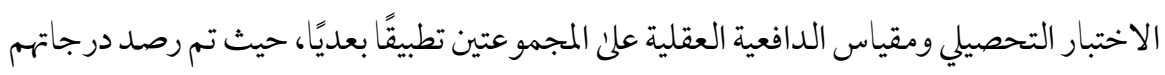

$$
\text { تمهيدًا لإجر اء المعالجة الإحصائية لها. }
$$$$
\text { خامسًا: المعالجات الإحصائية للبيانات }
$$

لكون البحث يستخدم المنهج شبه التجريبي الذي يهدف إلى قياس الفرق بين متوسط درجات طلاب المجموعتين التجريبية والضابطة وذلك للإجابة عن تساؤلات الدراسة؛ فإنَّ الباحث اعتمد الأساليب الإحصائية الأتية: - - معامل (التجزئة النصفية) لحساب ثبات الاختبار التحصيلي. 
- اختبار (ت) للعينات المستقلة Independent samples t test، للتعرف على دلالة الفروق بين

$$
\text { القياسين القبليين للمجموعتين الضابطة والتجريبية. }
$$

- اختبار (ت) للعينات المستقلة Independent samples t test، للتعرف علئ دلالة الفروق بين

$$
\text { القياسين البعديين للمجموعتين الضابطة والتجريبية. }
$$

$$
\begin{aligned}
& \text { - - مربع إيتا لقياس حجم الأثر. } \\
& \text { سادسًا: عرض نتائج البحث }
\end{aligned}
$$

ا ـ الإجابة عن السؤال الأول من أسئلة البحث والذي ينص على: ما معايير تصميم الفيديو الرقمي القائم على السرد القصصي في بيئة تعلم إلكترونية لتنمية الدافعية العقلية والتحصيل الأكاديمي لدى طلاب كلية التربية بجامعة الملك سعود؟ للإجابة عن هذا السؤال قام الباحث بتحديد معايير تصميم الفيديو الرقمي القائم على السرد القصي في بيئة تعلم إلكترونية لتنمية الدافعية العقلية والتحصيل الأكاديمي لدىن طلاب كلية التربية بجامعة الملك سعود، وتكونت هذه المعايير من (V) معايير رئيسية، و (YT) مؤشراً، وقد تم توضيح

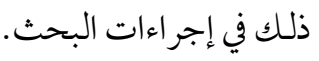

r. الإجابة عن السؤال الثاني من أسئلة البحث والذي ينص على: ما التصميم التعليمي للفيديو الرقمي القائم على السرد القصصي في بيئة تعلم إلكترونية لتنمية الدافعية العقلية والتحصيل الأكاديمي لدى لئي طلاب كلية التربية بجامعة الملك سعود؟ للإجابة عن هذا السؤال قام الباحث بالتصميم التعليمي للفيديو الرقمي القائم علن السرد القصي باتباع النموذج العام للتصميم التعليمي (ADDIE) وذلك وفق الإجراءات الآتية: التحليل، والتصميم، والتطوير، والتنفيذ، والتقويم، وقد تم توضيح ذلك في إجراءات البحث.

r. الإجابة عن السؤال الثالث من أسئلة البحث والذي ينص على: ما أثر الفيديو الرقمي القائم على السرد القصصي في بيئة تعلم إلكترونية في تنمية الدافعية العقلية لدى طلاب كلية التربية بجامعة الملك 
وللإجابة علن السؤال الثالث تم صياغة الفرضية الأتية: يوجد فرق ذو دلالة إحصائية عند مستوى (0 • , • ) بين متوسطي درجات المجموعة التجريبية التي استخدمت الفيديو الرقمي القائم علن السرد القصصي، والمجموعة الضابطة التي درست باستخدام الطريقة التقليدية، في التطبيق البعدي لمقياس الدافعية العقلية لصالح المجموعة التجريبية. وللتحقق من هذه الفرضية لمعرفة ما إذا كان هناك فرق ذو دلالة إحصائية بين متوسطي درجات المجموعتين التجريبية والضابطة في القياس البعدي لمقياس الدافعية العقلية، استخدم الباحث اختبار (ت) للعينات المستقلة Independent Samples t test، وفيا يلي عرض للنتائج التي أسفرت عنها نتائج

$$
\text { اختبار (ت)، كما هو موضح في الجدول (7). }
$$

جدول (7) اختبار (ت) للعينات المستقلة لتو ضيح دلالة الفروق بين متوسطي درجات أفرد المجموعة الضابطة والتجريبية في التطبيق البعدي علن مقياس الدافعية العقلية

\begin{tabular}{|c|c|c|c|c|c|c|c|}
\hline حربع (ايتا) & قيمة الدلالة & درجة الحرية & قيمة & الالنحراف & المتوسط & العدد & المجموعة \\
\hline \multirow{2}{*}{$\cdot, r v$} & & \multirow[t]{2}{*}{ 7. } & \multirow{2}{*}{$0,9 \pi r$} & $9, \wedge 1$ & $|10, r|$ & ru & الضابطة \\
\hline & & & & $11, \varepsilon r$ & $r \cdot 1, r r$ & $r \cdot$ & التجريبية \\
\hline
\end{tabular}

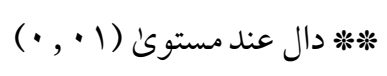

يتضح من الجلدول (7) تفوق طلاب المجموعة التجريبية في التطبيق البعدي لمقياس الدافعية،

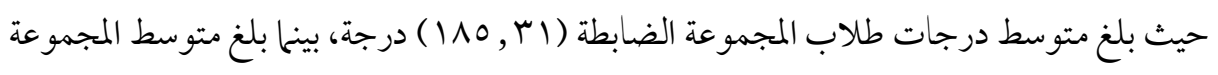

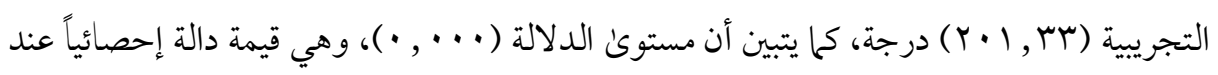
مستوئ دلالة اقل من (1 · , ·)، مما يشير إلى أن هناك فرق ذو دلالة إحصائية بين متوسطي درجات أفر اد المجموعة الضابطة والتجريبية في مقياس الدافعية العقلية في التطبيق البعدي. وأن قيمة مربع إيتا بالنسبة للفيديو الرقمي القائم علن السرد القصصي وأثره علن تنمية الدافعية العقلية لدى طلاب كلية التربية بجامعة الملك سعود بلغت (rV r • • ) وهي قيمة أكبر من القيمة الدالة علن الأهمية التربوية للنتائج الإحصائية في البحوث التربوية والنفسية ومقدارها (10 ر • ) حيث يري 
كوهين (Cohen, 1977) أن التأثير الذي يفسر (من 0 1\% فأكثر) من التباين الكلي لأي متغير مستقل

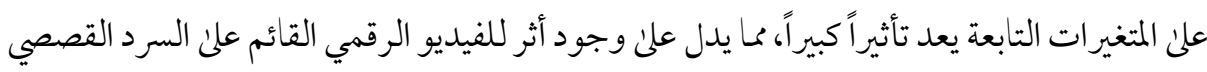
في بيئة تعلم إلكترونية في تنمية الدافعية العقلية لدئ طلاب كلية التربية بجامعة الملك سعود، حيث تبين أن قيمة (d) لحجم التأثير بلغت (ro ه , ( ) وهو يعد تأثير كبير كحا أشار (عفانة، ... . ب). ع. الإجابة عن السؤال الرابع من أسئلة البحث والذي ينص على: ما أثر الفيديو الرقمي القائم على السرد القصصي في بيئة تعلم إلكترونية في التحصيل الأكاديمي لدى طلاب كلية التربية بجامعة الملك

سeود؟

ولإجابة على السؤال الرابع تم صياغة الفرضية الآتية: يوجد فرق ذو دلالة إحصائية عند مستوى (0 • , • ) بين متوسطي درجات المجموعة التجريبية التي استخدمت الفيديو الرقمي القائم علن السرد القصصي، والمجموعة الضابطة التي درست باستخدام الطريقة التقليدية، في التطبيق البعدي للاختبار التحصيلي لصالح المجموعة التجريبية. وللتحقق من هذه الفرضية لمعرفة مـا إذا كان هناك فرق ذو دلالة إحصائية بين متوسطي درجات المجموعتين التجريبية والضابطة في القياس البعدي للاختبار التحصيلي، استخدم الباحث اختبار (ت) للعينات المستقلة Independent Samples t test، وفيا يلي عرض للنتائج التي أسفرت عنها نتائج اختبار (ت)، كما هو موضح في الجدول (7).

جدول (7) اختبار (ت) للعينات المستقلة لتوضيح دلالة الفروق بين متوسطي درجات أفرد المجموعة الضابطة والتجريبية في التطبيق البعدي للاختبار التحصيلي.

\begin{tabular}{|c|c|c|c|c|c|c|c|c|}
\hline حربح (ايتا) & قيمة الدلالة & درجة & قيمة & الالنحراف & المستوسط & العدد & المجموعة & \\
\hline \multirow{2}{*}{$\cdot, r_{\wedge}$} & \multirow{2}{*}{ ****, $\cdots$} & \multirow{2}{*}{7.} & \multirow{2}{*}{$7, .99$} & $r, r \varepsilon$ & $r, \mid r$ & rr & الضابطة & الاختبار \\
\hline & & & & $r, \varepsilon 1$ & ro,qr & $r$. & التجريبية & التحصيلي \\
\hline
\end{tabular}

http://dx.doi.org/10.29009/ijres.5.1.8 
يتضح من الجدول (V) تفوق طلاب المجموعة التجريبية في التطبيق البعدي للاختبار

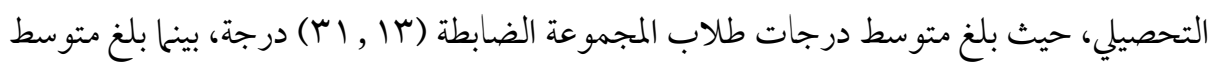

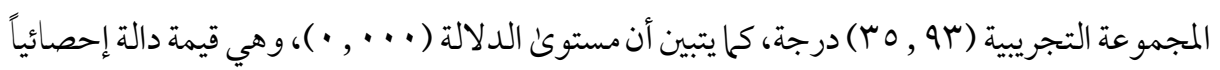
عند مستوى دلالة اقل من ( •)، مما يشير إلى أن هناك فرق ذو دلالة إحصائية بين متوسطي درجات أفراد المجموعة الضابطة والتجريبية في الاختبار التحصيلي في التطبيق البعدي. وأن قيمة مربع إيتا بالنسبة للفيديو الرقمي القائم علن السرد القصصي وأثره علن التحصيل لدىن

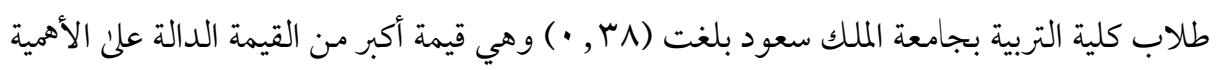
التربوية للنتائج الإحصائية في البحوث التربوية والنفسية ومقدارها (10 , ·) حيث يري كوهين(Cohen, 1977) أن التأثير الذي يفسر (من 0 (1) فأكثر) من التباين الكلي لأي متغير مستقل

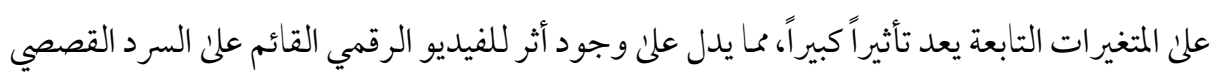
في بيئة تعلم إلكترونية في تنمية التحصيل لدنا طلاب كلية التربية بجامعة الملك سعود، حيث تبين أن قيمة (d) لحجم التأثير بلغت (d 07 , 1) وهو يعد تأثير كبير كما أشار (عفانة، ... ب).

\section{تفسير النتائج ومناقشتها}

أولاً: أثبتت النتائج فاعلية استخدام الفيديو الرقمي القائم على السرد القصصي في بيئة تعلم إلكترونية في تنمية الدافعية العقلية لدنا طلاب كلية التربية بجامعة الملك سعود، وهذا يعني أن الن استخدام الفيديو الرقمي القائم علن السرد القصصي في بيئة تعلم إلكترونية قد أدئ إلى تنشيط الدافعية العقلية لدى الطلاب أفراد عينة البحث، وهذا يرجع إلى أن الفيديو الرقمي يركز علن حاجات المتعلمين ويجذب انتباههم، وتتفق هذه النتائج مع نتائج دراسات كلا من دراسة أولافلين، وآخرون

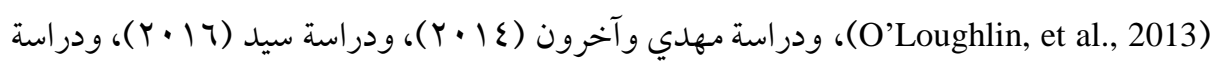

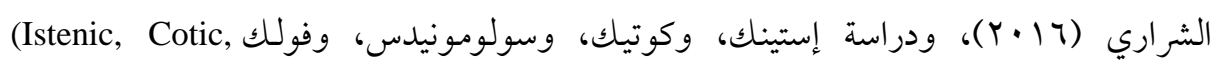
Solomonides, \& Volk, 2016) (Yhelton, Archambault, \& Hale., 2017) 
وحيث أن الدافعية العقلية تتكون من أربعة أبعاد، هي: التركيز العقلي، التوجه نحو التعلم، حل المشكلات إبداعيًا، والتكامل المعرفي، فيمكن تفسير نتائج هذا السؤال المي أن الفيديو الرقمي القائم علن السرد القصصي في بيئة تعلم إلكترونية يحقق كل هذه الأبعاد، فهو يحسن من استيعاب المتعلمين، ويعطي فرصة لخيالهم في تحليل وتفسير المحتوى التعليمي المقدم لهم، ويبعد الملل عنهم، ويوظف جميع الحواس لديهه، ويجعل عملية انتقال المعلومات سهلة وميسرة، ويضيف المتعة والتسلية إلى عملية التعليم والتعلم، ويكسب المتعلمين الدافعية العقلية، ومهارات النقد والحوار والتحليل. ثانيًا: أثبتت النتائج فاعلية استخدام الفيديو التعليمي الرقمي القائم علن السرد القصصي في بيئة تعلم إلكترونية في التحصيل الأكاديمي لدني طلاب كلية التربية بجامعة الملك سعود، وهذا يرجع إلى لى ما يتميز به الفيديو الرقمي من ميزات وإمكانيات متعددة، حيث يجمع بين الصوت والصورة والحركة. وتتفق هذه النتائج مع نتائج دراسات كلا من أوكياي، وكاند (Okyay \& Kand, 2017)، ودراسة بالمان (Balaman, 2017) ودراسة رحيمي، ويدو لاهي (Rahimi \& Yadollahi, 2017)، ودراسة سوالمه

فالفيديو الرقمي القائم علئ السرد القصصي يعد من أكثر الوسائط فاعلية لما يشتمل عليه من صوت وصورة وحركة تحكي قصة، ولتأثيره الكبير في تنمية الجموانب المعرفية والمهارية والوجدانية، ويرجع ذلك إلى أن السرد القصصي يعد أسلوبًا فعالًا للتأثير في المتعلمين، وتحريك مشاعرهم و انفعالاتهم، كما يعمل علن نقل المعارف والقيم والاتجاهات لهم بطريقة شيقة وممتعة. كما أنه يتضمن عرض الصوت والصورة والفيديو بإيقاع، وسرعة مناسبة بحيث يتتقل المتعلم من مشهد إلى آخر بتسلسل وترتيب منطقي وسرعة مناسبة. وما يتميز به من إمكانيات ومميزات عديدة، حيث يساعد على لئل تجسيد أحداث، وتقديمها للطلاب بكل يسر وسهولة وبطريقة تجذب انتباههم، وتساعدهم علن اكتساب عادات إيجابية أثناء مشاهدة الفيديو الرقمي القائم علن السرد القصصي، ولذلك فهو أسلوب فعال يساعد المتعلمين علن فهم المحتون التعليمي؛ لأنه يقدم محتوى الدرس بطريقة محبة تؤثر في نفوس المتعلمين من خلال المشاعر التي تحملها القصة. 
كما أن محاضرات الفيديو الرقمية القائمة علن السرد القصصي تكون الصور بها واضحة،

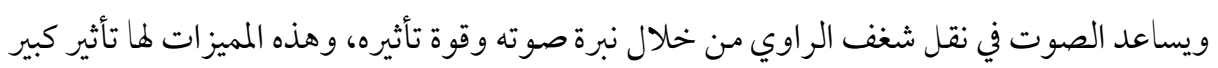
في تسهيل التعلم وتحسين التعليم، ولا تكون متاحة في التعليم التقليدي.

$$
\text { التوصيات: في ضوء نتائج البحث، يوصي البحث بالآتي: }
$$

1 - توجيه أنظار الباحثين إلى التوسع في تقديم أنواع أخرى من أساليب غختلفة للفيديو الرقمي القائم

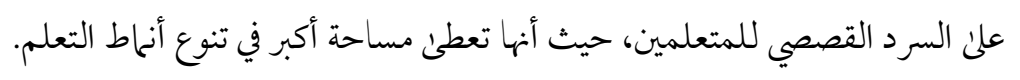

r- توجيه أنظار مصممي ومطوري الفيديو هات الرقمية باستخدام السرد القصصي فيها. r- الاهتحام بيئات القصة الرقمية المختلفة وإدخاها في التعلم بشكل عام. ع- تدريب أعضاء هيئة التدريس بالجمامعات السعودية علن إنتاج محاضرات الفيديو القائمة علن السرد القصصي، واستخدامها من خلال منصة البلاكبورد. المقترحات: في ضوء نتائج البحث، يوصي البحث بالآتي: 1 - إجراء المزيدمن البحوث والدراسات التي تتناول متغيرات وأساليب أخرىن للفيديو الرقمي القائم علن السرد القصصي. r - إجراء المزيد من البحوث والدراسات التي تتناول دراسة العلاقة بين أساليب الفيديو الرقمي القائم علن السرد القصصي وخصائص المتعلمين. بـ - دراسة اتجاهات الطلاب حول استخدام الفيديو الرقمي القائم علن السرد القصصي. ع- دراسة فاعلية استخدام الفيديو الرقمي القائم علن السرد القصصي علن متغيرات أخرى غير التي

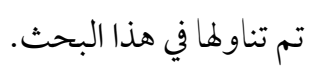


أممد، ياسر أحمد. (9 (r). التعثر في التحصيل الأكاديمي للطالب الجامعي الأسباب والحلول، مجلة

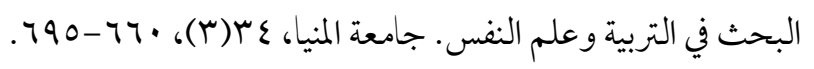

إسكندر، رامي زكي، وإبراهيم، رشا أحمد. (1) · ب). أثر اختلاف أنهاط تقديم نصوص الفيديو الرقمي بنظرية الحمل المعرفي علن اكتساب الطلاب مقرر حقوق الإنسان تكنولوجيًا والاتجاه

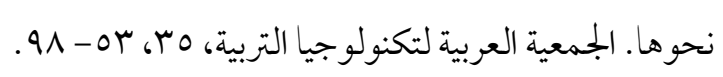

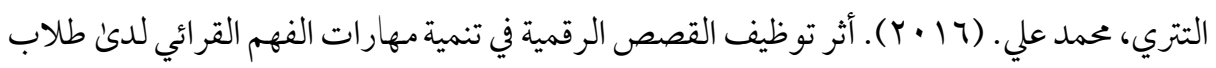

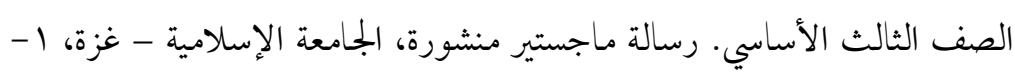

جامع، حسن حسيني، وأبو عيطة، جوهرة درويش، وسويدان، أمل عبد الفتاح. (Y • (Y). فاعلية

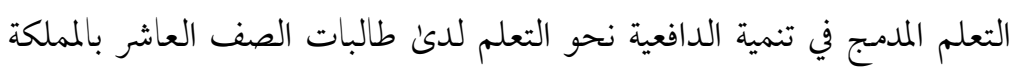

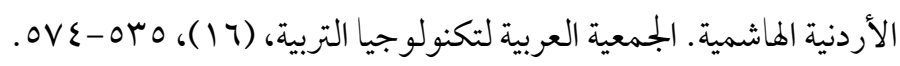

جبر، رضا عبد الرازق. ( (Y · ). فاعلية برنامج قائم علن عادات العقل في تنمية مهارات اتخاذ القرار

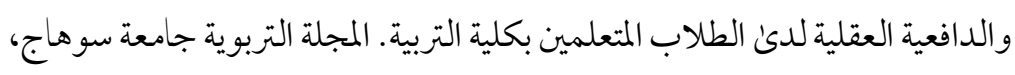

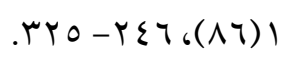

حرب، سليان أمد. (1) · Y). فاعلية التعلم المقلوب بالفيديو الرقمي (العادي/ التفاعلي) في تنمية

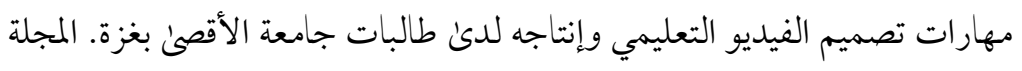

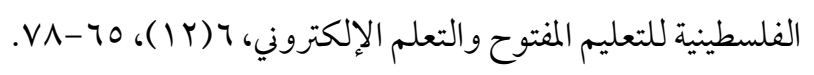

خميس، محمد عطية. (10 • ( ). مصادر التعلم الإلكتروني (الجزء الأول: الأفرادو الوسائط)، القاهرة:

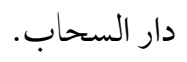

http://dx.doi.org/10.29009/ijres.5.1.8 
خميس، محمد عطية. (· · · (Y). اتجاهات حديثة في تكنولوجيا التعليم وبجالات البحث فيها (الجزء

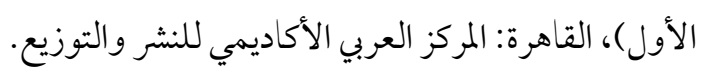

رشيد، فارس هارون. (9 ا • r). الدافعية العقلية وعلاقتها بالتوافق الأكاديمي لدئ طلبة الدراسات

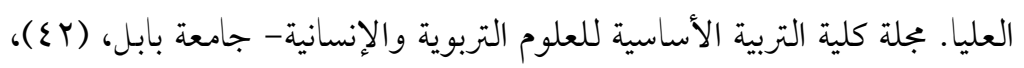

$$
.1 \cdot 19-1 \cdot v r
$$

الزهد، إسلام. (1) • ( ). أثر استخدام سرد القصص الرقمي على مهارات المحادثة والدافعية لدني

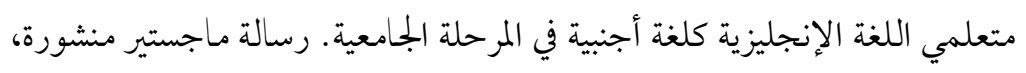

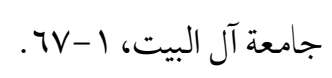

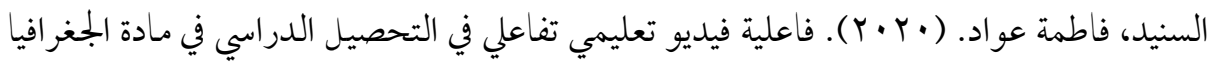
لدئ طالبات الصف السادس الأساسي في مدارس محافظة مأدبا. رسالة ماجستير

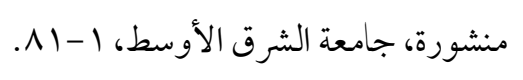

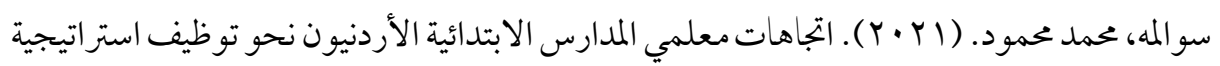
السرد القصصي في مادة الرياضيات. المجلة الأكاديمية في العلوم التربوية والنفسية،

$$
.0 \cdot-r V_{6}(r) r
$$

السيد، صباح عبد الله. (Y PV). برنامج مقترح قائم علن استخدام القصص الرقمية لتنمية بعض المفاهيم الرياضية والتفكير الابتكاري لدىن طفل رياض الأطفال. دراسات عربية في

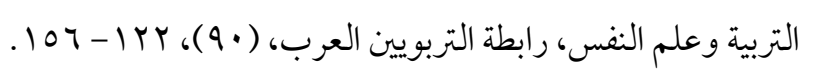

سيد، هويدا محمود. (Y (Y (Y). أثر تصميم قصص رقمية في تاريخ الرياضيات في تنمية مهارات تصميمها ومعتقدات دمج تاريخ الرياضيات في تدريسها لدئ المعلم قبل الخدمة.

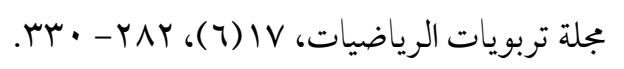


الشراري، عايد محمد. (7 ( • (Y). أثر طريقة السرد القصصي في تنمية الأنماط اللغوية وعادات العقل

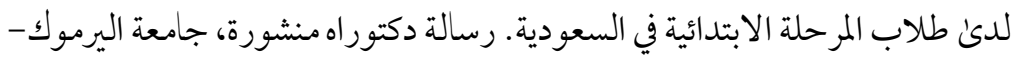

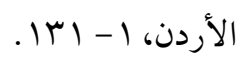

الشريم، أحمد علي. (7 ( ) ). القدرة التنبؤية للدافعية العقلية بالتحصيل الأكاديمي لدئ عينة من طلبة جامعة القصيم. مجلة الدراسات التربوية والنفسية، جامعة السلطان قابوس، • (Y)،

$$
\text { . } \wedge \text { ^ - rV }
$$

عبد الرحيم، طارق نور الدين. (1) • r). عادات العقل، الدافعية العقلية، التخصص الدراسي والجنس كمتغيرات تنبؤيه لكفاءة التعلم الإيجابية لدى طلاب جامعة سوهاج. المجلة التربوية-

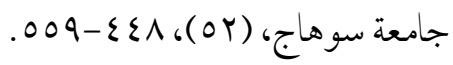

العبيدي، صباح مرشود، والعزاوي، أمل جدوع. (·r · r). الدافعية العقلية وعلاقتها بأساليب التعلم

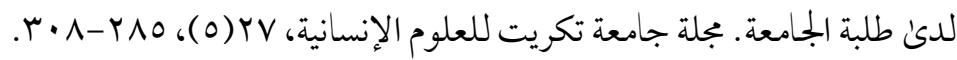
العجرمي، سامح جميل. (9 1 ). فاعلية مقاطع الفيديو التعليمية عبر اليوتيوب في تنمية مهارات إنتاج القصص الرقمية لدن طالبات كلية التربية بجامعة الأقصن واتجاهاتهن نحو استخدام

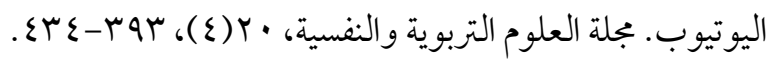

عطا الله، محمد إبر اهيم. (1 ( • ( ). فعالية برنامج إرشادي معرفي انفعلي سلوكي لتنمية الدافعية الذاتية الأكاديمية وأثره علن خفض التسويف الأكاديمي لدى المتعثرين دراسياً من طلاب

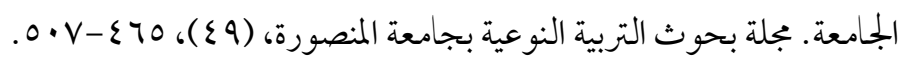

القضاة، محمد فرحان، والعسيري، محمد علي. (0 • ( ). العلاقة بين التعلم المنظم ذاتيا والدافعية العقلية لدئ طلاب كلية التربية بجامعة الملك سعود. مركز بحوث كلية التربية-

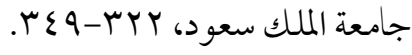


الكندري، إبر اهيم عبد اله. ( • • · ). فاعلية التعلم من الأقران في تحسين التحصيل الدراسي والدافعية

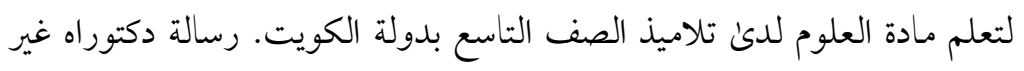
منشورة، الجلمعة الإسلامية العالمية ماليزيا.

مرعي، توفيق أحد، ونوفل، محمد بكر . (1 · ( ). الصورة الأردنية الاولية لمقياس كاليفورنيا للدافعية العقلية: دراسة ميدانية علئ طلبة كلية العلوم التربوية الجامعية الأونروا في الأردن. مجلة

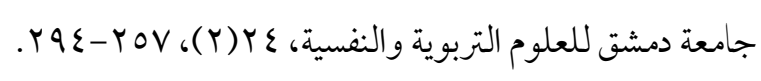

المطيري، سلطان هويدي. (Y) · r). التعليم الإلكتروني خيار إستراتيجي. الرياض، مكتبة الملك فهد الوطنية.

مناديلو، إيـان أحم، وعوض، أمـاني محمد. (1) • (Y). معايير تصميم استراتيجية السرد القصصي بيئة تعلم إلكتروني لتنمية مهارات الاتصال اللغوي في اللغة الإنجليزية لدى تلاميذ

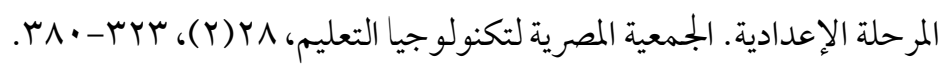

مهدي، حسن ربحي، ودرويش، عطا حسن، والجرف، ريم سعد. (ع ا ·r). فاعلية استراتيجية في القصص الرقمية في اكساب طالبات الصف التاسع الأساسي المفاهيم التكنولوجيا بغزة. بجلة جامعة القدس المفتوحة للأبحاث والدراسات التربوية والنفسية، ع(ب ا )،

$$
.11 \cdot-1 \leqslant 0
$$

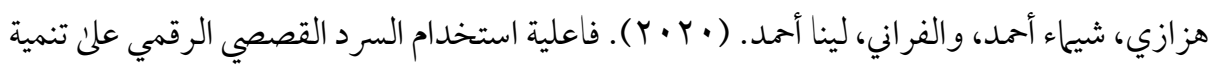
فهم المسموع لأطفال مرحلة ما قبل المدرسة. المجلة السعودية للعلوم التربوية، (TV)،

$$
\text { . } \varepsilon \varepsilon-r_{0}
$$




\section{References}

Abdel Rahim, T. N. (2018). Habits of Mind and Mental motivation as predictor variables for positive learning competence for sohag university students, (in Arabic). Journal of Educational - Sohag University, (52), 448-559.

Ahmed, Y.A. (2019). The low academic achievement of the students university side Causes and solutions, (in Arabic). Journal of Research in Education and Psychology, Minia University, 34(3), 660-695.

AL- godhah, M. F., \& AL-asiri, M.A. (2015). Relationship between self-organized learning and mental motivation of students in the Faculty of Education of King Saud University, (in Arabic). College of Education Research Center, King Saud University,322-349.

AL- kandari, E. A. (2020). the effectiveness of the Peer Instruction approach in improving academic achievement and motivation among the ninth-grade science students in the State of Kuwait, (in Arabic). UnPublished PhD thesis, International Islamic University Malaysia.

Al- motairi, S. H. (2021). E-learning is a strategic choice, Riyadh, King Fahd National Library.

Al-obaidi, S. M.,\& Al-azzawi, A. j. (2020). Mental motivation and its relationship to learning methods of university students, (in Arabic). Journal of Tikrit University for Humanities, 27(5), 285-308.

Al-shararI, A. M. (2016).The effect of the Storytelling in Developing Langusge Patterns and Mind Habits Among Basic Stage Students in saudi Arabia, (in Arabic). Published PhD thesis, Yarmook University, 1-131.

Al-shraim, A. A. (2016). Ability of Mental Motivation to Predict Academic Achievement among a Sample of Qassim University Students, (in Arabic). Journal of Educational and Psychological Studies, Sultan Qaboos University, 10(2), 376-389.

Alsnaid, F. A. (2020). The Effectiveness of Interactive Video on the Academic Achievement in Geography for Sixth Grades in Madaba Governorate Schools, (in Arabic). published Master's Thesis, Middle East University, $1-81$. 
Altattri, M.A. (2016). The effect of employing digital stories in developing the reading comprehension skills of third grade students, (in Arabic). published Master's Thesis, Islamic University of Gaza, 1-191.

Alzohd, E. (2018). The effect of digital storytelling on Undergraduate EFL Learnings' speaking skills and motivation, (in Arabic). published Master's Thesis, Al Albayt University, 1-67.

Atallah, M. I. (2018). The Effectiveness of Cognitive Emotional Behavioral Counseling Program for Developing Academic Self-Motivation and its Effect on Reducing Academic Procrastination among Academic Defaulters University Students, (in Arabic). Research Journal Specific Education, Mansoura University, (49), 465-507.

Balaman, F. (2017). The effects of digital storytelling on the students' project based virtual learning qualifications. Curr Res Educ, 3(32), 81-94.

Beheshti, M., Taspolat, A., Kaya, S. O. \& Sapanca, F. H. (2018). Characteristics of instructional videos. World Journal on Educational Technology: Current Issues. 10(1), 061-069.

Chtouki, Y., Harroud, H., Khalidi, M., \& Bennani, S. (2012). The impact of YouTube videos on the student's learning. In 2012 international conference on information technology based higher education and training (ITHET) (pp. 1-4).

Dehaimesh, A. R. (2016). The effects of using storytelling strategy on developing tenth grade EFL learner' speaking skill and motivation in Jordan. M. A. Thesis, Faculty of Educational Sciences, Al-el- Bayt University, Jordan.

El-agrami, S. j. (2019). The Effectiveness of Using Educational Video Clips on YouTube To Develop Digital Storytelling Production Skills among Female Students at the Faculty of Education at AL-Aqsa University and their Attitudes towards Using YouTube, (in Arabic). Journal of Educational Sciences and psychological, 20(4), 393-434.

EL-sayed, S. A. (2017). A proposed program based on the Digital Storytelling to Develop some Mathematical Concepts and Creative Thinking for Kindergarten Children, (in Arabic) Arab studies in education and psychology, Arab Educational Association, (90), 122-156. 
Gabr, R. A. (2021). The Effectiveness of a Program Based on the Habits of Mind in Developing Decision-Making Skills and Mental Motivation among Student Teachers at the Faculty of Education, (in Arabic). Journal of Education Sohag University, 1(86), 246-325.

Harb, S. A. (2018). The effectiveness of two types of flipped learning with digital video (normal and interactive) in developing the skills of designing and producing the educational video among the female students at Al-Aqsa University of Gaza, (in Arabic). Palestinian Journal of open Learning \& e-Learning, 6(12), 65-78.

Hazazy, S. A., \& al-frani, L. A. (2020). The Effectiveness of Using Digital Storytelling in Improving Preschool Children's Listening Comprehension, (in Arabic). Saudi Journal for Educational Sciences, (67), 25-44.

Hsu, C. K., Hwang, G. J., Chang, Y. T., \& Chang, C. K. (2013). Effects of video caption modes on English Listening Comprehension and vocabulary acquisition using handheld devices. Educational Technology \& Society, 16(1), 403414.

Iskandar, R. Z, \& Ibrahim, R. A. (2018). The impact of different forms of digital video delivery on the knowledge load theory on students' acquisition of technology and orientation, (in Arabic). Arab Society for Educational Technology, 35, 53-98.

Istenic S. A., Cotic, M., Solomonides, I., \& Volk, M. (2016). Engaging preservice primary and preprimary school teachers in digital storytelling for the teaching and learning of mathematics. British Journal of Educational Technology, 47(1), 29-50

jamie, H. H., Abu Attia, J. D., \& Swedan, A. A. (2012). The effectiveness of blended learning in developing the motivation towards learning among tenth grade students in the Hashemite Kingdom of Jordan, (in Arabic). Arab Society for Educational Technology, (16), 535-574.

Khamis, M. A. (2015). E-Learning Resources: Individuals and Media, (in Arabic). Dar Al-Sahab for Publishing and Distribution, Cairo.

Khamis, M. A. (2020). Recent Trends in Education Technology and Research (Part I) (in Arabic). Cairo: Arab Academic Publishing and Distribution Centre. 
Lin, H. M., Chen, W. J., Nien, S. F. (2014). The Study of Achievement and Motivation by e-Learning - A Case Study. International Journal of Information and Education Technology. 4(5), 421-425.

Lindgren, R., Pea, R., Lewis, S., \& Rosen, J. (2007). Learning from digital video: An exploration of how interactions affect outcome. Proceedings of the 8th international conference on Computer supported collaborative learning CSCL, 2007, pp. 447-449.

Mahdi, H. R., Darwish, Ah., \& Al-Jarf, R. S. (2014). The Effectiveness of the Strategy of Digital Storytelling in the Acquisition of Technological Concepts in Basic Ninth Grade Students in Gaza, (in Arabic). Journal of Al-Quds Open University for Educational and Psychological Research and Studies, 4(13), 145-180.

Manadilo, E. A., \& Awad, A. M. (2018). Rubrics for Designing a Digital Storytelling Strategy in an e-learning Environment for Enhancing Language Communication Skills in English for Preparatory Stage Students, (in Arabic). Egyptian Association for Educational Technology, 28(2), 323380.

Marei, T. A., \& Nofal, M. B. (2008). Jordan's initial picture of California's mental Motivation scale, (in Arabic). Damascus University Journal for Educational and Psychological Science, 24(2), 257-294.

O’Loughlin, J., Nichroinın, D., \& O’Grady, D. (2013). Digital video: The impact on children's learning experiences in primary physical education. European Physical Education Review, 19(2), 165-182.

Okyay, O.\& Kand, A. (2017). Impact of the Interactive Story Reading Method on Receptive and Expressive Language Vocabulary of Children European, Journal of Educational Research, (2), 375-406.

Oweis, T. I. (2018). Effects of using a blended learning method on students' achievement and motivation to learn English in Jordan: A pilot case study. Education research international, Article ID 7425924, 1-7

Rahimi, M., \& Yadollahi, S. (2017). Effects of offline vs. online digital storytelling on the development of EFL learners' literacy skills. Cogent Education, $4(1), 1-13$. 
Rashid, F. H. (2019). Mental motivation and its relation to academic compatibility among postgraduate students, (in Arabic). Basic Education College Magazine For Educational and Humanities Sciences, Babylon University, (42), 1073-1089.

Sawalmeh, M. M. (2021). Jordanian Primary School Teachers' Attitudes towards Using the Storytelling Strategy in Math Course: Empirical Study, (in Arabic). International Academic Journal in Educational and Psychological Sciences, 2(2), 37-50.

Sayid, H. M. (2016). The Effect of Designing Digital Stories on The History of Mathematics on Developing Their Design Skill and Beliefs of Integrating the History of Mathematics Into Its Teaching for Pre-Service Female Teacher, (in Arabic). Journal of Mathematics Education, 17(6), 282-330.

Shelton, C. C., Archambault, L. M., \& Hale, A. E. (2017). Bringing Digital Storytelling to the Elementary Classroom: Video Production for Preservice Teachers. Journal of Digital Learning in Teacher Education, 33(2), 58-68

Vieira, I., Lopes, A. P., \& Soares, F. (2014). The potential benefits of using videos in higher education. In Proceedings of EDULEARN14 Conference, 7th-9th July 2014, Barcelona, Spain, 0750-0756.

Yousef, A. M. F., Chatti, M. A., \& Schroeder, U. (2014). Video-based learning: A critical analysis of the research published in 2003-2013 and future visions. The Sixth International Conference on Mobile, Hybrid, and Online Learning, 112-119. 
